\title{
Multi-small molecule conjugations as new targeted delivery carriers for tumor therapy
}

\author{
This article was published in the following Dove Press journal: \\ International Journal of Nanomedicine \\ I September 2015 \\ Number of times this article has been viewed
}

\section{Lingling Shan' \\ Ming Liu ${ }^{2}$ \\ Chao Wu' \\ Liang Zhao' \\ Siwen $\mathrm{Li}^{3}$ \\ Lisheng $\mathrm{Xu}^{\prime}$ \\ Wengen Cao' \\ Guizhen Gao' \\ Yueqing $\mathrm{Gu}^{3}$}

'Institute of Pharmaceutical

Biotechnology, School of Biology and

Food Engineering, Suzhou University,

Suzhou, People's Republic of China;

${ }^{2}$ Department of Biology, University

of South Dakota, Vermillion, SD,

USA; ${ }^{3}$ Department of Biomedical

Engineering, School of Life Science and Technology, China Pharmaceutical University, Nanjing, People's

Republic of China
Correspondence: Yueqing Gu

Department of Biomedical Engineering,

School of Life Science and Technology,

China Pharmaceutical University, Nanjing

210009 , People's Republic of China

Tel +86 25 83271046

Fax +86 $258327 \quad 1249$

Email guyueqingsubmission@hotmail.com
Abstract: In response to the challenges of cancer chemotherapeutics, including poor physicochemical properties, low tumor targeting ability, and harmful side effects, we developed a new tumor-targeted multi-small molecule drug delivery platform. Using paclitaxel (PTX) as a model therapeutic, we prepared two prodrugs, ie, folic acid-fluorescein-5(6)-isothiocyanatearginine-paclitaxel (FA-FITC-Arg-PTX) and folic acid-5-aminofluorescein-glutamic-paclitaxel (FA-5AF-Glu-PTX), composed of folic acid (FA, target), amino acids (Arg or Glu, linker), and fluorescent dye (fluorescein in vitro or near-infrared fluorescent dye in vivo) in order to better understand the mechanism of PTX prodrug targeting. In vitro and acute toxicity studies demonstrated the low toxicity of the prodrug formulations compared with the free drug. In vitro and in vivo studies indicated that folate receptor-mediated uptake of PTX-conjugated multi-small molecule carriers induced high antitumor activity. Notably, compared with free PTX and with PTX-loaded macromolecular carriers from our previous study, this multi-small molecule-conjugated strategy improved the water solubility, loading rate, targeting ability, antitumor activity, and toxicity profile of PTX. These results support the use of multi-small molecules as tumor-targeting drug delivery systems.

Keywords: multi-small molecules, paclitaxel, prodrugs, targeting, tumor therapy

\section{Introduction}

Water solubility is one of the most important physicochemical properties of a medicine or prodrug. Adequate aqueous solubility is important for toxicity studies, drug testing, and clinical application. ${ }^{1}$ Looking at the physicochemical properties of marketed drugs and those in clinical development, most hydrophobic drugs with poor water solubility have been discontinued. ${ }^{2}$ Developing a prodrug is one of the best strategies for achieving enhanced chemical or metabolic stability and higher water solubility. ${ }^{3}$ A prodrug can also have increased targeting ability, improved oral or local absorption, and reduced toxicity, and cause less local irritation. ${ }^{4}$

Paclitaxel (PTX) is a potential antitumor compound and a front-line chemotherapeutic used in the treatment of a variety of cancers. ${ }^{5}$ However, the current formulations have severe side effects related to low water solubility $(0.4 \mu \mathrm{g} / \mathrm{mL}) .{ }^{6}$ To improve its water solubility, decrease its toxicity, increase its bioavailability, and achieve a better therapeutic effect, nanobased delivery systems have been developed for PTX, using liposomes, ${ }^{7}$ micelles, ${ }^{8}$ polymers,${ }^{9}$ inorganic nanoparticles,,${ }^{10}$ human serum albumin, ${ }^{11}$ and polyethylene glycol-polylactic acid. ${ }^{12}$ Further, an albumin-bound PTX nanoparticle formulation (Abraxane ${ }^{\circledR}$ ) has been approved by the US Food and Drug Administration to treat metastatic breast cancer and non-small-cell lung cancer. ${ }^{13}$ However, the free drug-loading rates for these prodrug formulations are relatively low. For example, the PTX loading rate for the human serum albumin and polyethylene glycol-polylactic acid 
formulations is about $10.0 \mathrm{wt} \%$ and $16.7 \mathrm{wt} \%$, respectively. ${ }^{14}$ In clinical practice, some patients also experience significant undesirable side effects because of the emulsifier. Whether Abraxane ${ }^{\circledR}$ could improve survival and overcome P-glycoprotein-mediated drug resistance is still unclear. ${ }^{15}$ While we have previously developed protein-carrier prodrug formulations to enhance the solubility and targeting ability of PTX, some problems have remained unresolved, such as the low PTX content and high immunotoxicity. ${ }^{16}$ Therefore, there is still a pressing need to develop alternative PTX formulations. Esterification with amino acids has been shown to be a useful approach for increasing aqueous solubility and bioavailability. ${ }^{17}$ In this work, PTX was derivatized at its 2 '-hydroxy function by esterification with amino acids.

Folic acid (FA) has been identified as a ligand for selective delivery of therapeutic agents to cancer cells. ${ }^{18}$ Uptake of FA into cells is mediated by the FA receptor. ${ }^{19}$ The human folate receptor alpha (FR- $\alpha$ ) has high affinity for the FA ligand, and is currently considered an essential component in the cellular accumulation of FA used in chemotherapy. ${ }^{20}$ FR- $\alpha$ expression is very low in most normal cells and tissues or not detectable, but is upregulated and detectable in ovarian, breast, brain, lung, and colorectal cancers. ${ }^{21}$ In our previous work, we investigated an FA-modified drug delivery system and found that covalently attached FA can increase the ability to target FR-positive tumors. ${ }^{22}$

Biomedical optics is a rapidly expanding imaging field with direct applications in cellular biology, pharmacology, and diagnosis of disease. ${ }^{23}$ The small molecule fluorescein is widely used as a fluorescent dye in studies designed to elucidate the structures and mechanisms of drug delivery systems. ${ }^{24}$ In this work, the water-soluble fluorescent dye, fluorescein-5(6)-isothiocyanate (FITC) and 5-aminofluorescein (5AF) were used to label PTX and detect cellular uptake of the prodrug in vitro, along with its pharmacokinetics and biodistribution. Near-infrared fluorescence imaging has many advantages as a non-invasive technique for real-time in vivo monitoring of biological information in living subjects without use of ionizing radiation. ${ }^{25}$ Our research group has successfully developed a hydrophilic ICG derivative (ICG-Der-02) to trace the dynamic behavior of prodrugs in nude mice, and its tumor targeting ability has been demonstrated. ${ }^{16,22}$

In this study, PTX was derivatized at its 2 '-hydroxy function using Fmoc-Arg(Pbf)-OH and Fmoc-Glu(OtBu)-OH as linkers. The carboxyl groups of the linkers were covalently attached to FA by formation of amide bonds to produce FA-Arg-PTX and FA-Glu-PTX. Small molecule fluorescent dye, FITC/5AF, was then used to label FA-FITC-Arg-PTX and FA-5AF-Glu-PXT prodrugs by amide bond. The release properties of the parent drug PTX from the ester bond of the PTX linker were investigated. The toxicity of the prodrug was studied by in vitro and acute toxicity $\left(\mathrm{LD}_{50}\right)$ testing. Dynamic behavior and tumor targeting ability were investigated by in vitro and in vivo optical imaging. Finally, the therapeutic efficacy of the synthesized prodrug was evaluated by in vitro and in vivo studies.

\section{Materials and methods Materials}

PTX (molecular weight 853.9) was purchased from JiangSu Research Institute (Wuxi, People's Republic of China). FA (molecular weight 441.4), dicyclohexylcarbodiimide, N-hydroxysuccinimide (NHS), Fmoc-L-arginine acid(Pbf)-OH (Fmoc-Arg[Pbf]-OH, molecular weight 648.77), FmocL-glutamic acid 5-tert-butyl ester (Fmoc-Glu[OtBu]-OH, molecular weight 425.49), FITC (molecular weight 389.38), and 5AF (molecular weight 347.32) were purchased from commercial sources. ICG-Der-02 (molecular weight 995) was prepared in our laboratory. All other solvents and reagents used in this study were certified analytical reagent grade and from Sigma Chemicals (St Louis, MO, USA).

\section{Synthesis of multi-small molecule- conjugated PTX targeted complex Synthesis of FA-Arg(Pbf)-PTX and FA-Glu(OtBu)-PTX}

FA-Arg(Pbf)-PTX and FA-Glu(OtBu)-PTX were synthesized in four steps, as shown in Figure 1Aa-Ad and $\mathrm{Ba}-\mathrm{Bd}$, respectively. Briefly, PTX (100 mg, $0.117 \mathrm{mmol}$, 1 equivalent) and Fmoc-Arg(Pbf)-OH (91.08 mg, 0.14 mmol, 1.2 equivalents) were dissolved in $10 \mathrm{~mL}$ of $\mathrm{CH}_{2} \mathrm{Cl}_{2}$, and 4-dimethylaminopyridine (14.27 $\mathrm{mg}, 0.117 \mathrm{mmol}, 1$ equivalent) was subsequently added (Figure 1Aa). Cold EDC (44.85 mg, $0.234 \mathrm{mmol}, 2$ equivalent, $5 \mathrm{~mL}$ of $\mathrm{CH}_{2} \mathrm{Cl}_{2}$ ) was added dropwise to the mixture over 20 minutes and stirred at room temperature for 22 hours. The reaction mixture was diluted further with $15 \mathrm{~mL}$ of $\mathrm{CH}_{2} \mathrm{Cl}_{2}$. The organic layer was washed with water, saturated aqueous $\mathrm{NaHCO}_{3}$, and dried over $\mathrm{MgSO}_{4}$. The residue obtained after evaporation (vacuum) of the organic solvent was purified by recrystallization from diethyl ether. The purified Fmoc-Arg(Pbf)-PTX was obtained as a white solid in $85 \%$ yield. This product was used in the next step without further characterization. Next, 44.14 $\mathrm{mg}$ of FA $(0.1 \mathrm{mmol})$ in $5 \mathrm{~mL}$ of dimethyl sulfoxide was 

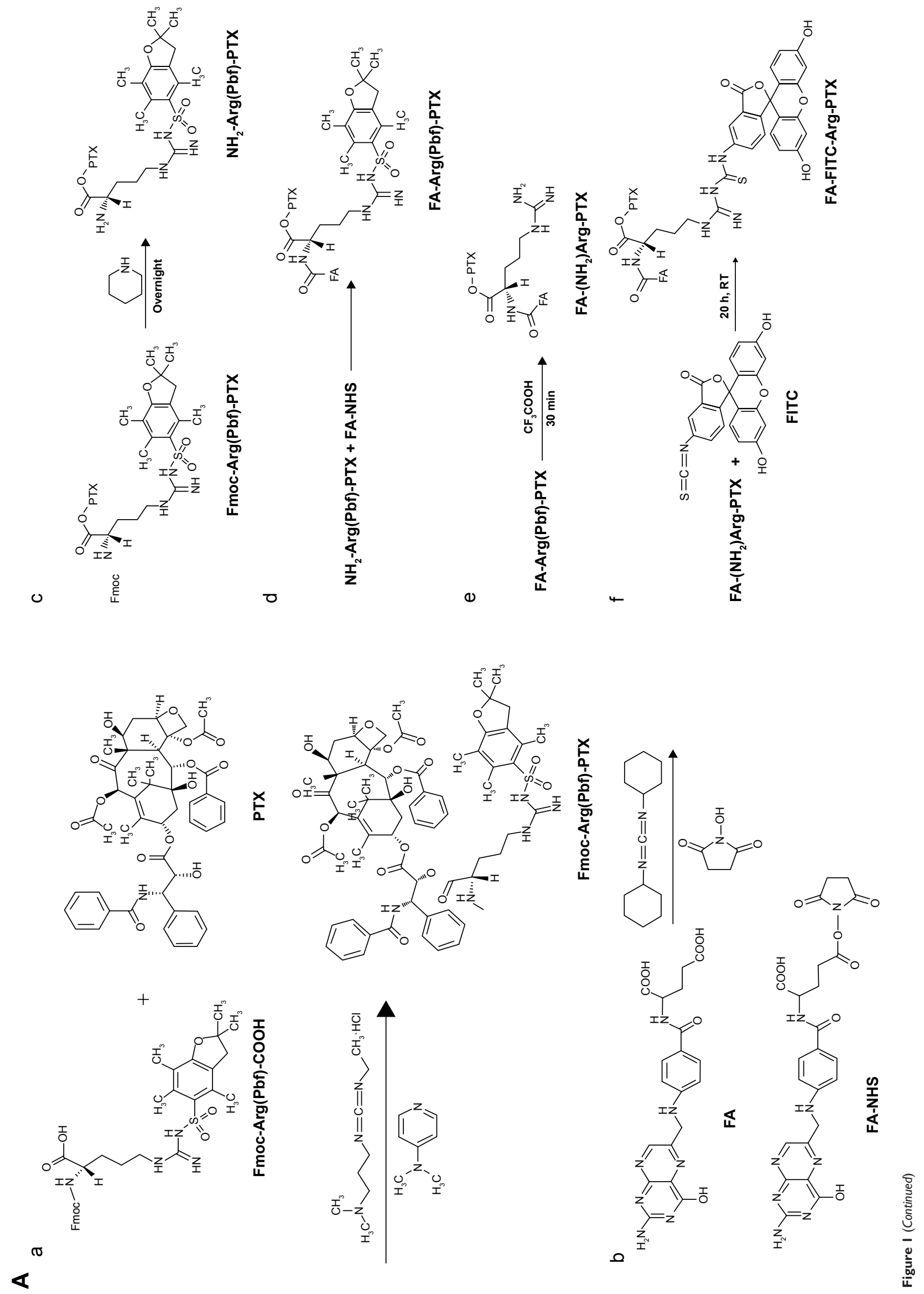

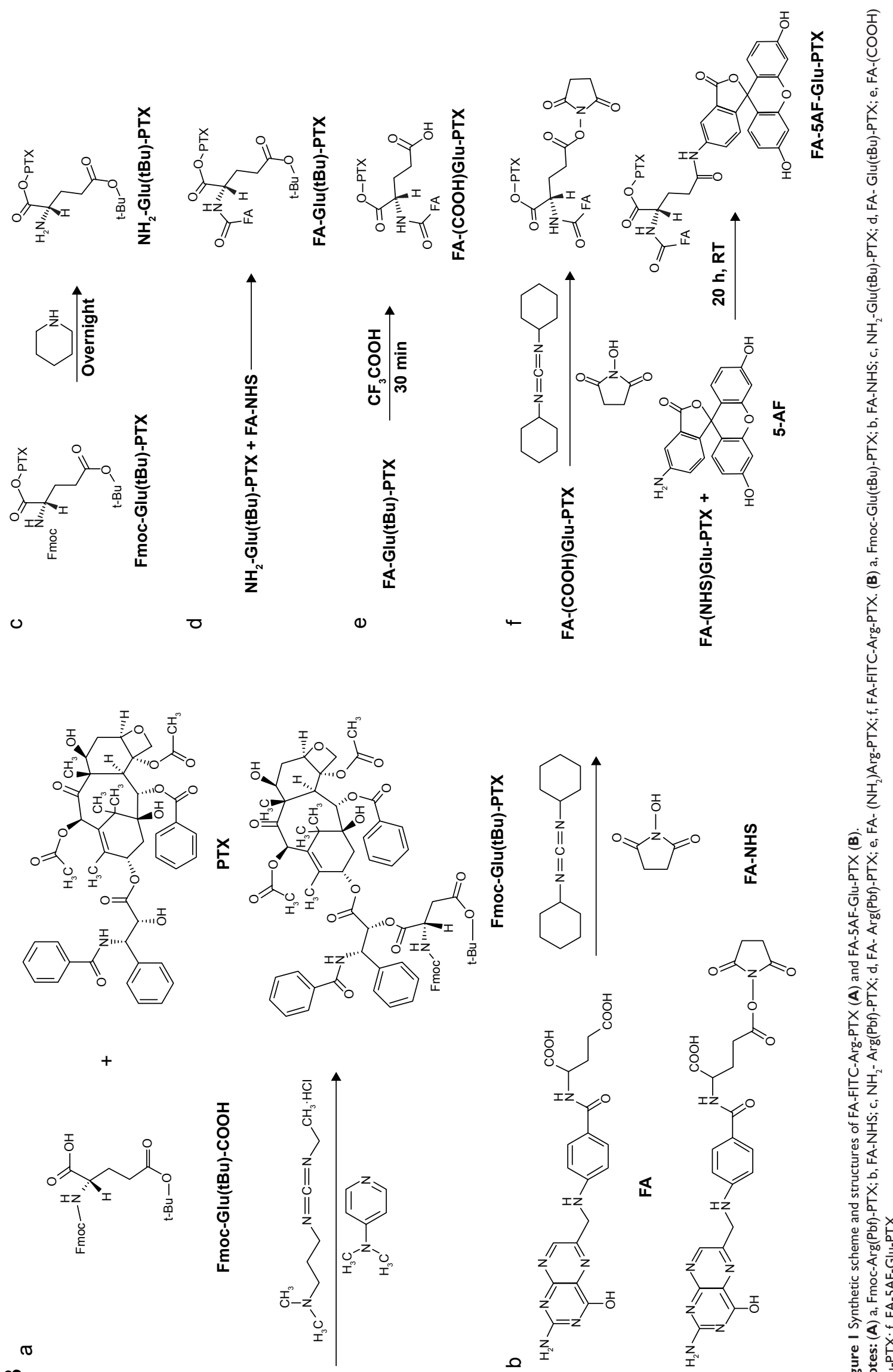

m<smiles>[CH]OC(=O)CC[C@@]([CH])(C(=O)[O-])C(OC)OC</smiles>
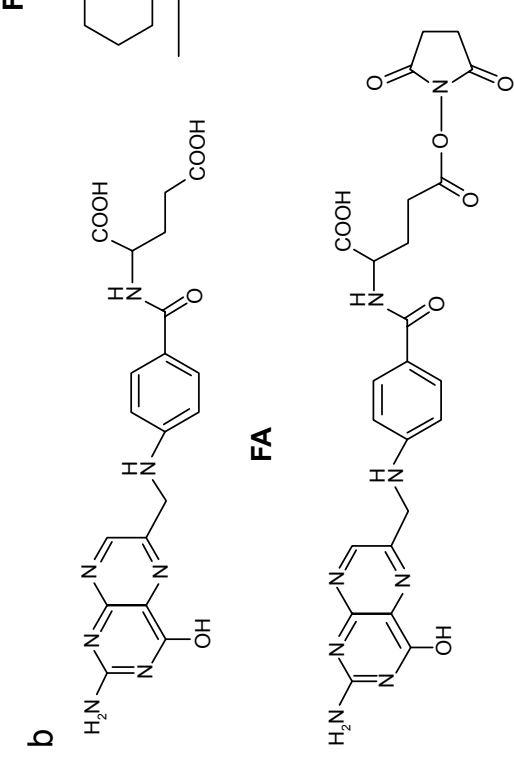
activated with dicyclohexylcarbodiimide and NHS (molar ratio of FA to dicyclohexylcarbodiimide to NHS, 1:1.5:1.5) at room temperature in the dark for 5 hours (Figure $1 \mathrm{Ab}$ ). The residue was removed by filtration under reduced pressure, and the activated FA was extracted with anhydrous acetone. Fmoc-Arg(Pbf)-PTX (150.3 mg, $0.1 \mathrm{mmol}$ ) was dissolved in $10 \mathrm{~mL}$ of $\mathrm{CH}_{2} \mathrm{Cl}_{2}, 2 \mathrm{~mL}$ of 2-pipecoline was added to the solvent for deprotection, and the mixture was stirred at room temperature for 10 hours (Figure 1Ac). The residue obtained after evaporation (vacuum) of the organic solvent was purified by recrystallization from diethyl ether. The purified $\mathrm{NH}_{2}$ $\operatorname{Arg}(\mathrm{Pbf})-\mathrm{PTX}$ was obtained as a white solid in 95\% yield. The molecular weight of the purified $\mathrm{NH}_{2}-\mathrm{Arg}(\mathrm{Pbf})-\mathrm{PTX}$ was determined by liquid chromatography mass spectrometry (LC-MS), $\mathrm{NH}_{2}$-Arg[Pbf]-PTX: MS (electrospray ionization [ESI], m/z): 1,279.43 $\left([\mathrm{M}+\mathrm{H}]^{+}\right), \mathrm{NH}_{2}$-Glu(tBut)-PTX: MS (ESI, m/z): 1,056.15 ([M + H $\left.]^{+}\right)$. $\mathrm{NH}_{2}-\operatorname{Arg}(\mathrm{Pbf})-\mathrm{PTX}$ (127.94 mg, $0.1 \mathrm{mmol}$ ) was dissolved in dimethyl sulfoxide, and the activated FA-NHS was added to the mixture, which was then stirred at room temperature in the dark for 24 hours (Figure 1Ad). The reaction mixture was concentrated in a vacuum and purified on a silica gel column. The purified FA-Arg(Pbf)-PTX was obtained as a yellow solid in $85 \%$ yield. A procedure similar to that described above was also applied to synthesize the control FA-Glu(OtBu)-PTX (Figure $1 \mathrm{Ba}-\mathrm{Bd})$. These two products were used in the next step without further characterization.

\section{Synthesis of FA-FITC-Arg-PTX and FA-5AF- Glu-PTX targeted prodrugs}

FA-FITC-Arg-PTX and FA-5AF-Glu-PTX were synthesized in two steps (Figure 1Ae-Af and Be-Bf, respectively). As shown in Figure 1Ae, FA-Arg(Pbf)-PTX (172.1 mg, $0.1 \mathrm{mmol}$, 1 equivalent) was dissolved in $4 \mathrm{~mL}$ of dimethyl sulfoxide, and $3 \mathrm{~mL}$ of trifluoroacetic acid was subsequently added. The mixture was stirred at room temperature for 30 minutes. The FA- $\left(\mathrm{NH}_{2}\right)$ Arg-PTX obtained after evaporation (vacuum) of the organic solvent was purified by recrystallization from diethyl ether. The purified FA- $\left(\mathrm{NH}_{2}\right)$ Arg-PTX was obtained as a yellow solid in $80 \%$ yield. The molecular weight of the purified FA- $\left(\mathrm{NH}_{2}\right)$ Arg-PTX was determined by LC-MS. FA- $\left(\mathrm{NH}_{2}\right)$ Arg-PTX: MS (ESI, m/z): 1,468.5 ([M + H] $]^{+}$. Finally, the activated $38.93 \mathrm{mg}$ FITC was added in $5 \mathrm{~mL}$ of dimethyl sulfoxide buffer containing FA-( $\left.\mathrm{NH}_{2}\right)$ Arg-PTX (146.85 mg, $0.1 \mathrm{mmol}$, molar ratio 1:1), as shown in Figure 1Af. After 12 hours, the reaction mixture was purified on a silica gel column. The purified FA-FITC-Arg-PTX was obtained as a brown solid in $65 \%$ yield. The molecular weight of the purified FA-FITC-Arg-PTX was determined by LC-MS. FA-FITC-Arg-PTX: MS (ESI, m/z): 1,857.88 $[\mathrm{M}+\mathrm{H}]^{+}$. In order to investigate the dynamics of this small molecule-conjugated PTX targeted delivery system, the nearinfrared fluorescent dye ICG-Der-02(COOH) was attached to FA-( $\left.\mathrm{NH}_{2}\right)$ Arg-PTX and $\mathrm{NH}_{2}-\mathrm{Arg}(\mathrm{Pbf})$-PTX by a method similar to that described previously. The purity of the FAICG02-Arg-PTX and ICG02-( $\left.\mathrm{NH}_{2}\right)$ Arg-PTX was determined by thin layer chromatography.

Next, $3 \mathrm{~mL}$ of triethylamine was added to $5 \mathrm{~mL}$ of FA-Glu(OtBu)-PTX (in Figure 1Be), and the mixture was stirred at room temperature for 30 minutes. FA-Glu(OtBu)PTX was removed from the protective-OtBu group to form FA-(COOH)Glu-PTX. The reaction mixture was purified by recrystallization from diethyl ether. The purified FA- $(\mathrm{COOH})$ Glu-PTX was obtained as a yellow solid in $78 \%$ yield. The molecular weight of the purified FA- $(\mathrm{COOH}) \mathrm{Glu}-\mathrm{PTX}$ was determined by LC-MS. FA-(COOH)Glu-PTX: MS (ESI, $\mathrm{m} / \mathrm{z}): 1,447.4\left([\mathrm{M}+\mathrm{H}]^{+}\right)$. The activated FA-(NHS)GluPTX was dissolved in $5 \mathrm{~mL}$ of dimethyl sulfoxide containing $34.73 \mathrm{mg} 5 \mathrm{AF}$ (molar ratio is 1:1, Figure 1B-f). After 16 hours, the reaction mixture was purified using a silica gel column to remove the unconjugated FA-(NHS)Glu-PTX and $5 \mathrm{AF}$ fragments. The purified FA-5AF-Glu-PTX was obtained as a light brown solid in $60 \%$ yield. The molecular weight of the purified FA-5AF-Glu-PTX was also determined by LC-MS.

\section{Characterization of FA-FITC-Arg-PTX and FA-5AF-Glu-PTX}

To confirm the components of the above synthesized compounds, FA-FITC-Arg-PTX, FA-5AF-Glu-PTX, ICG02-( $\left.\mathrm{NH}_{2}\right)$ Arg-PTX, and FA-ICG02-Arg-PTX were evaluated by spectroscopic measurement at $365 \mathrm{~nm}, 220$ nm, $227 \mathrm{~nm}, 347 \mathrm{~nm}, 492 \mathrm{~nm}$, and $780 \mathrm{~nm}$, which correspond to the absorption peaks of FA, Arg, PTX, FITC, 5AF, and ICG-Der-02, respectively. Successful conjugation of PTX to the small molecules was further confirmed by LC-MS and high-performance liquid chromatography (HPLC, Shimadzu).

\section{Physical and chemical properties of FA- FITC-Arg-PTX and FA-5AF-Glu-PTX}

The physical and chemical properties of the PTX prodrug formulations, including their drug loading (ie, amount of PTX), aqueous solubility, and stability, were then determined. The amount of conjugated PTX in FA-FITC-Arg-PTX or FA-5AF-Glu-PTX 
was evaluated using theoretical methods and a standard curve of HPLC peak area versus PTX content (anhydrous ethyl alcohol). The aqueous solubility of the conjugated PTX was determined using a method reported elsewhere. ${ }^{26}$ At room temperature $\left(25^{\circ} \mathrm{C}\right), 100 \mathrm{mg}$ of conjugated PTX was placed in a $10 \mathrm{~mL}$ volumetric flask to which $500 \mu \mathrm{L}$ of water was added by injector. After saturation was reached, the aqueous solubility of the two prodrugs was measured. To investigate the stability of the ester bond in the FA-FITC-Arg-PTX and FA-5AF-Glu-PTX compounds, the free PTX released from the derivatives was measured in different types of medium, including phosphatebuffered saline (PBS, pH 7.4) and human plasma at $37^{\circ} \mathrm{C}$ for up to 12 hours. The PTX-conjugated products $(5 \mathrm{mg}$ each of FA-FITC-Arg-PTX and FA-5AF-Glu-PTX) were dissolved in $2.5 \mathrm{~mL}$ of each type of medium. Next, $100 \mu \mathrm{L}$ of each sample was taken at a designated time point. The free PTX was then extracted using $1.5 \mathrm{~mL}$ of ethyl acetate and measured by reverse-phase HPLC on a C18 column $(300 \mathrm{~mm} \times 3.9 \mathrm{~mm}$; Nova-Pak, Waters) with an acetonitrile/water gradient (mobile phase consisting of methanol to water (45/45), $1 \mathrm{~mL}$ per minute at $30^{\circ} \mathrm{C}$, PTX: $227 \mathrm{~nm}$ ).

\section{In vitro studies}

\section{Cell culture}

Human breast cancer (MDA-MB-231, MCF-7), human lung cancer (A549), and human renal epithelial (HEK293) cell lines were purchased from the American Type Culture Collection and cultured at $37^{\circ} \mathrm{C}$ in a humidified atmosphere containing 5\% $\mathrm{CO}_{2}$ in Dulbecco's Modified Eagle's Medium and Roswell Park Memorial Institute 1640 medium supplemented with $10 \%$ fetal bovine serum, $100 \mathrm{U} / \mathrm{mL}$ penicillin, and $100 \mu \mathrm{g} / \mathrm{mL}$ streptomycin. The use of these cell lines were approved by the ethics committee of Suzhou University, Suzhou, People's Republic of China.

\section{Cellular uptake of multi-small molecule-conjugated PTX targeted prodrugs}

The above four cell lines (MDA-MB-231, MCF-7, A549, and HEK293) were used to evaluate FA- $\alpha$ receptor protein expression by Western blot analysis, and were prepared as described previously. ${ }^{20}$ Tumor cells and normal mammary cells were washed twice at room temperature in PBS and harvested by scraping in cold lysis buffer containing PBS, $1 \%$ NP40, 0.5\% sodium deoxycholate, $0.1 \%$ sodium dodecyl sulfate, $0.1 \mathrm{mg} / \mathrm{mL}$ phenylmethyl sulfonyl fluoride, $2 \mu \mathrm{g} / \mathrm{mL}$ aprotinin, and $1 \mathrm{mmol} / \mathrm{L}$ sodium orthovanadate. After 20 minutes in an ice bath, the lysates were passed through a 21-gauge needle, incubated on ice for another 30 minutes, and then centrifuged at $15,000 \times g$ for 20 minutes at $4^{\circ} \mathrm{C}$.
Protein concentrations were determined using the Pierce Micro bicinchoninic acid protein assay reagent, and the proteins were stored at $-80^{\circ} \mathrm{C}$.

The multi-small molecule-conjugated PTX-targeted prodrugs were labeled with visible fluorescent dye (FITC and 5AF) for fluorescence microscopy. The three types of cells were seeded in 6-well plates and incubated in culture medium overnight, followed by incubation in a $200 \mu \mathrm{L}$ solution of FA-FITCArg-PTX or FA-5AF-Glu-PTX (1 mg/mL) for 8 hours. After washing with PBS, the cells were directly visualized by fluorescence microscopy ( $40 \times$ objective magnification).

Cell cytometry was used to further quantify the uptake of FA-FITC-Arg-PTX and FA-5AF-Glu-PTX in the cell lines. Briefly, $5 \times 10^{5}$ cells were seeded in 6 -well plates and incubated in culture medium overnight. Next, $200 \mu \mathrm{L}$ of $1 \mathrm{mg} / \mathrm{mL}$ FA-FITC-Arg-PTX and FA-5AF-Glu-PTX were added into each well. After 8 hours of incubation at $37^{\circ} \mathrm{C}$, the cells were resuspended in $500 \mu \mathrm{L}$ of PBS. The cell suspension was immediately analyzed by flow cytometry.

\section{Cell viability assay}

To evaluate the antitumor activity and cytotoxicity of FAFITC-Arg-PTX and FA-5AF-Glu-PTX, MTT assays were conducted on the MDA-MB-231, MCF-7, A549, and HEK293 cell lines following a standard protocol. ${ }^{18}$ The cells were plated at a density of $5 \times 10^{3}$ cells/well in 96-well plates and then incubated for 48 hours with PTX, FA-FITC-Arg-PTX (theoretically conjugated PTX 45.93\%), and FA-5AF-Glu-PTX (theoretically conjugated PTX $47.71 \%$ ) at the same concentrations in the range of $0.3125-1 \mu \mathrm{g} / \mathrm{mL}$. The concentration of conjugated PTX was $0.01435-0.4771 \mu \mathrm{g} / \mathrm{mL}$. Each drug was tested in six wells. MTT solution $(20 \mathrm{~mL}, 5 \mathrm{mg} / \mathrm{mL})$ was then added into each well. The absorbance of the solution in each well was measured at $490 \mathrm{~nm}$ using a multi-well plate reader.

\section{Apoptosis study}

To further investigate the efficacy of the prodrugs in the three tumor cell lines, cell apoptosis was qualitatively and quantitatively studied. Briefly, fluorescence microscopy was used to identify the various morphological changes during apoptosis. Propidium iodide (PI), which binds to DNA once the cell membrane had become permeable, was used to identify cell apoptosis. We also used flow cytometry to quantify apoptosis. ${ }^{20}$ After 24 hours of incubation with free PTX, FA-FITC-ArgPTX, or FA-5AF-Glu-PTX $(200 \mu \mathrm{L}, 1 \mathrm{mg} / \mathrm{mL})$, the cells were washed three times with PBS ( $\mathrm{pH} 7.0)$ before addition of $500 \mu \mathrm{L}$ of binding buffer and $5 \mu \mathrm{L}$ of PI to the mixture. The cells were directly visualized by fluorescence microscopy. To quantify apoptosis after 24 hours of incubation, the medium was 
discarded and the cells were resuspended in $500 \mu \mathrm{L}$ of binding buffer, and $5 \mu \mathrm{L}$ of PI were added to the mixture. The cell suspension was immediately analyzed by flow cytometry.

\section{In vivo studies}

\section{Animal subjects and tumor model}

The study protocol was approved by the Animal Ethical and Welfare Committee of Suzhou University, Suzhou, People's Republic of China. All animal experiments were carried out in compliance with the animal management regulations of the Ministry of Health, People's Republic of China (document 55, 2001) and the guidelines for the care and use of laboratory animals at Suzhou University.

MDA-MB-231, MCF-7, and A549 tumor cells with relatively high FR- $\alpha$ expression were implanted in the upper right axillary fossa in nude mice (each group, $n=5$ ). When the tumors had grown to a diameter of $0.2-0.5 \mathrm{~cm}$, the mice were investigated for drug targeting ability and therapeutic effect.

\section{Acute toxicity $\left(\mathrm{LD}_{50}\right)$ test in mice}

The acute toxicity of PTX, FA-FITC-Arg-PTX, and FA-5AFGlu-PTX was investigated in normal (Kunming) mice purchased from Charles River Laboratories. ${ }^{27}$ Briefly, 150 ICR mice (aged 3-4 weeks, weight 18-22 g) were divided into five groups of ten mice each to receive PTX $(15,20,25,30$, $45 \mathrm{mg} / \mathrm{kg}$ ), FA-FITC-Arg-PTX, or FA-5AF-Glu-PTX (80, $160,200,280,320 \mathrm{mg} / \mathrm{kg})$. Each group of mice contained equal numbers of males and females. The above prodrugs (in $0.2 \mathrm{~mL}$ ) were injected via the tail vein in each mouse. The mice were injected with $50 \%$ of the lethal dose determined in the $\mathrm{LD}_{50}$ studies. After 14 days, all mice were euthanized by $\mathrm{CO}_{2}$ asphyxiation followed by cervical dislocation to monitor for tissue changes.

\section{Dynamics and targeting ability of PTX based on multi-small molecule carriers in tumor-bearing mice}

Nude mice bearing MDA-MB-231 tumors were used to investigate the dynamics and targeting ability of the prodrug formulations ( $\mathrm{n}=5$ in each group). ICG02-( $\left.\mathrm{NH}_{2}\right) \operatorname{Arg}-\mathrm{PTX}$ $(0.2 \mathrm{~mL}, 5 \mathrm{mg} / \mathrm{kg})$ and FA-ICG02-Arg-PTX (0.2 mL, $5 \mathrm{mg} / \mathrm{kg}$ ) were administered to mice via tail vein injection. Fluorescence imaging was acquired using a near-infrared imaging method as reported previously. ${ }^{16}$ Tumor-to-normal $(\mathrm{T} / \mathrm{N})$ tissue contrast ratios were calculated by using the region of interest function of Living Image ${ }^{\circledR}$ software. $^{22}$

In addition, the successfully conjugated PTX prodrug including the fluorescent dye (FITC, 5AF), FA-FITC-Arg-PTX $(0.2 \mathrm{~mL}, 5 \mathrm{mg} / \mathrm{kg})$, and FA-5AF-Glu-PTX $(0.2 \mathrm{~mL}, 5 \mathrm{mg} / \mathrm{kg})$ were injected into the mice bearing MDA-MB-231 tumors $(n=5)$ via the tail vein. The mice were euthanized post-injection at a designated time point, and tissue was excised for sectioning and direct visualization by fluorescence microscopy.

\section{Antitumor activity}

Nude mice bearing MCF-7 and A549 tumors were randomly assigned to four groups ( $\mathrm{n}=5$ per group) and treated every 3 days by tail vein injection of PBS ( $\mathrm{pH} 7.4$, control), pure PTX solution ( $5 \mathrm{mg} / \mathrm{kg}$ ), FA-FITC-Arg-PTX ( $5 \mathrm{mg} / \mathrm{kg}$ ), or FA-5AF-Glu-PTX (5 mg/kg). Five tail vein injections were given every 3 days, with each dose in $0.2 \mathrm{~mL}$ of solution. The therapeutic efficacy and systemic toxicity of the two prodrug formulations was assessed by daily recording of tumor volume and body weight.

\section{Statistical analysis}

All data are reported as the mean \pm standard deviation of $n$ independent measurements. The statistical analysis was performed using the Student's $t$-test, with statistical significance assigned at a $P$-value of $<0.05$.

\section{Results}

\section{Characterization of targeted multi-small molecule-conjugated PTX prodrugs}

FA-FITC-Arg-PTX and FA-5AF-Glu-PTX were synthesized according to the procedures described in Figure 1. The absorption and fluorescence spectra for FA-FITC-Arg-PTX and FA-5AF-Glu-PTX showed all absorption peaks of the constituent components (FA, Arg/Glu, PTX, FITC/5AF, and ICG02 at $365 \mathrm{~nm}, 220 \mathrm{~nm}, 227 \mathrm{~nm}, 375 / 465 \mathrm{~nm}$, and $780 \mathrm{~nm}$, respectively) in the complex, indicating successful conjugation of the two prodrug formulations, which was further confirmed by LC-MS and HPLC, as shown in Figures S1 and S2. FA-FITC-Arg-PTX: MS (ESI, m/z): $1858.88[\mathrm{M}+\mathrm{H}]^{+}$, FA-5AF-Glu-PTX: MS (ESI, m/z): $1789.75[\mathrm{M}+\mathrm{H}]^{+}$(thin layer chromatography, Figure S2). In addition, the fluorescence of ICG-Der-02 was observed from the band of purified FA-ICG02-Arg-PTX and ICG02-( $\left.\mathrm{NH}_{2}\right)$ Arg-PTX using a near-infrared imaging system, which further demonstrated that ICG-Der-02 was attached to FA- $\left(\mathrm{NH}_{2}\right)$ Arg-PTX or $-\left(\mathrm{NH}_{2}\right)-\operatorname{Arg}(\mathrm{Pbf})-\mathrm{PTX}$ (Figure S2D).

\section{Physicochemical properties of FA-FITC- Arg-PTX and FA-5AF-Glu-PTX}

PTX loading in the prodrug formulations was evaluated by the standard curve for HPLC peak area versus PTX content. The regression equation for the standard PTX curve was $Y(O D)=65535.65035+17388.99822 \times$ 
$\left(R^{2}=0.99922\right)$. The linear range of the standard curve was $0.85-95.18 \mu \mathrm{g} / \mathrm{mL}$. PTX loading in the two prodrug formulations was $38.70 \% \pm 0.49 \%$ and $32.19 \% \pm 0.35 \%(n=5)$, respectively. To quantify the aqueous solubility of the multi-small molecule-conjugated PTX prodrug formulations, the direct observations were followed in the solubility calculations of the PTX prodrug formulations, FA-FITCArg-PTX (6.45 $\pm 0.15 \mathrm{mg} / \mathrm{mL}, \mathrm{n}=4)$ and FA-5AF-Glu-PTX $(6.41 \pm 0.18 \mathrm{mg} / \mathrm{mL}, \mathrm{n}=4)$ as shown in Figure S3. To investigate the cleavage of the linkers (Arg/Glu) in the products we measured the amount of free PTX released from the compounds after incubation of the products in PBS ( $\mathrm{pH} 7.4)$ and human plasma, respectively, at $37^{\circ} \mathrm{C}$. The free PTX was measured by HPLC, as shown in Figure S4A and B. The release profiles are given in Figure 2E. The FA-FITC-Arg-PTX/ FA-5AF-Glu-PTX formulation released PTX more rapidly in human plasma $(56.72 \% / 54.84 \%, 4$ hours $)$ and released less PTX in PBS (25.8\%/23.3\%, 4 hours).

\section{In vitro cell targeting}

To explain the receptor-mediated targeting of multi-small molecule-conjugated PTX vectors to HEK293, MDA-MB-231, MCF-7, and A549 cells, expression levels of FR- $\alpha$ protein were investigated by Western blot, and were found to be in the following order: MDA-MB-231 > MCF-7 > A549> HEK293, as shown in Figure 3A.

Uptake of these compounds in the cell lines was imaged by fluorescence microscopy and the results are shown in Figure 3B. The two tested PTX prodrug formulations showed increased uptake by tumor cells overexpressing FR- $\alpha$ (ie, MDA-MB-231, MCF-7, and A549) when compared with normal HEK293 cells. Flow cytometry indicated that the FA-FITC-Arg-PTX and FA-5AF-Glu-PTX formulations were taken up into MDAMB-231 cells at a rate of $89.6 \%$ and $85.9 \%$, respectively, and were retained at rate of $78.1 \%$ and $75.1 \%$ in MCF-7 cells and $63.2 \%$ and $59.0 \%$ in A549 cells; however, they were taken up by HEK293 cells at a rate of $2.1 \%$ and $1.9 \%$ (Figure 3C). These findings suggest that the FA modification enhanced the targeting ability of the two PTX prodrug formulations to tumors overexpressing FR- $\alpha$, and their uptake in the three tumor cell lines was consistent with FR- $\alpha$ protein levels.

\section{In vitro antitumor activity of FA-FITC- Arg-PTX and FA-5AF-Glu-PTX}

The cell viability ratio assay was used to qualitatively determine in vitro the antitumor activity and cytotoxicity of FAFITC-Arg-PTX and FA-5AF-Glu-PTX in MDA-MB-231, MCF-7, and A549 cancer cells. and in normal HEK293 cells.
The results are shown in Figure 4A. All the drug formulations showed dose-dependent antitumor activity at the different PTX concentrations. In the three tumor cell lines, the inhibition ratios of FA-FITC-Arg-PTX and FA-5AF-Glu-PTX were over $78.1 \%$ of total cells, whereas PTX inhibited a maximum of $62.4 \%$ of total cells. Importantly, the concentration of free PTX at each point was 2-fold when compared with the corresponding conjugated PTX formulation. A high concentration of free PTX still showed a lower tumor inhibition rate when compared with the conjugated PTX. In addition, the inhibition rates achieved by FA-FITC-Arg-PTX and FA5AF-Glu-PTX were not significantly different in any of the cell lines tested. All drugs displayed an increased inhibition ratio for MDA-MB-231 tumor cells with relatively high-level expression of FR- $\alpha$ when compared with MCF-7 and A549. Moreover, the two prodrug formulations showed a very high viability rate in normal HEK293 cells, even at the highest concentration $(0.459 \mu \mathrm{g} / \mathrm{mL})$. These findings suggest that multi-small molecule-conjugated PTX delivery systems have low cytotoxicity to normal cells and enhance the antitumor ability of free PTX in tumors overexpressing FR- $\alpha$.

By staining cells with PI, it is possible to distinguish and analyze nonapoptotic cells, late apoptotic cells (PI-positive, red), and necrotic cells (PI-positive, red). ${ }^{22}$ The cells were also examined under fluorescence microscopy. The results of a representative experiment are shown in Figure 4B. The necrotic cells (PI-positive) were clearly displayed in three tumor cell lines with free PTX, FA-FITC-Arg-PTX, and FA-5AF-Glu-PTX. Flow cytometry quantitative analyses indicated that the number of late apoptosis/necrotic value (Q4) of the three cell lines (MDA-MB-231, MCF-7, and A549) was 25.8/36.5\%/34.1\%, $19.9 \% / 26.7 \% / 27.9 \%$, and $14.6 \% / 16.8 \% / 16.3 \%$, respectively (Figure 4C). The above qualitative and quantitative analyses demonstrate that the PTX-conjugated multi-small molecule greatly enhanced the antitumor activity of low-dose PTX.

\section{Acute toxicity}

Surviving animals in the PTX group are indicated with a vertical line on the survival graph (Figure 5). The survival rate of animal in the different dose PTX group (from $15 \mathrm{mg} / \mathrm{kg}$ to $45 \mathrm{mg} / \mathrm{kg}$ ) has decreased from $90 \%$ to $0 \%$. Regardless of the dose of FA-FITC-Arg-PTX or FA-5AFGlu-PTX (from 80 to $320 \mathrm{mg} / \mathrm{kg}$ ), all groups of animals maintained their original survival rates. No histological difference was observed between the FA-FITC-Arg-PTX and FA-5AF-Glu-PTX group post-injection (data not shown). All results demonstrated that the cytotoxicity of the doses of prodrugs was low to mice. 

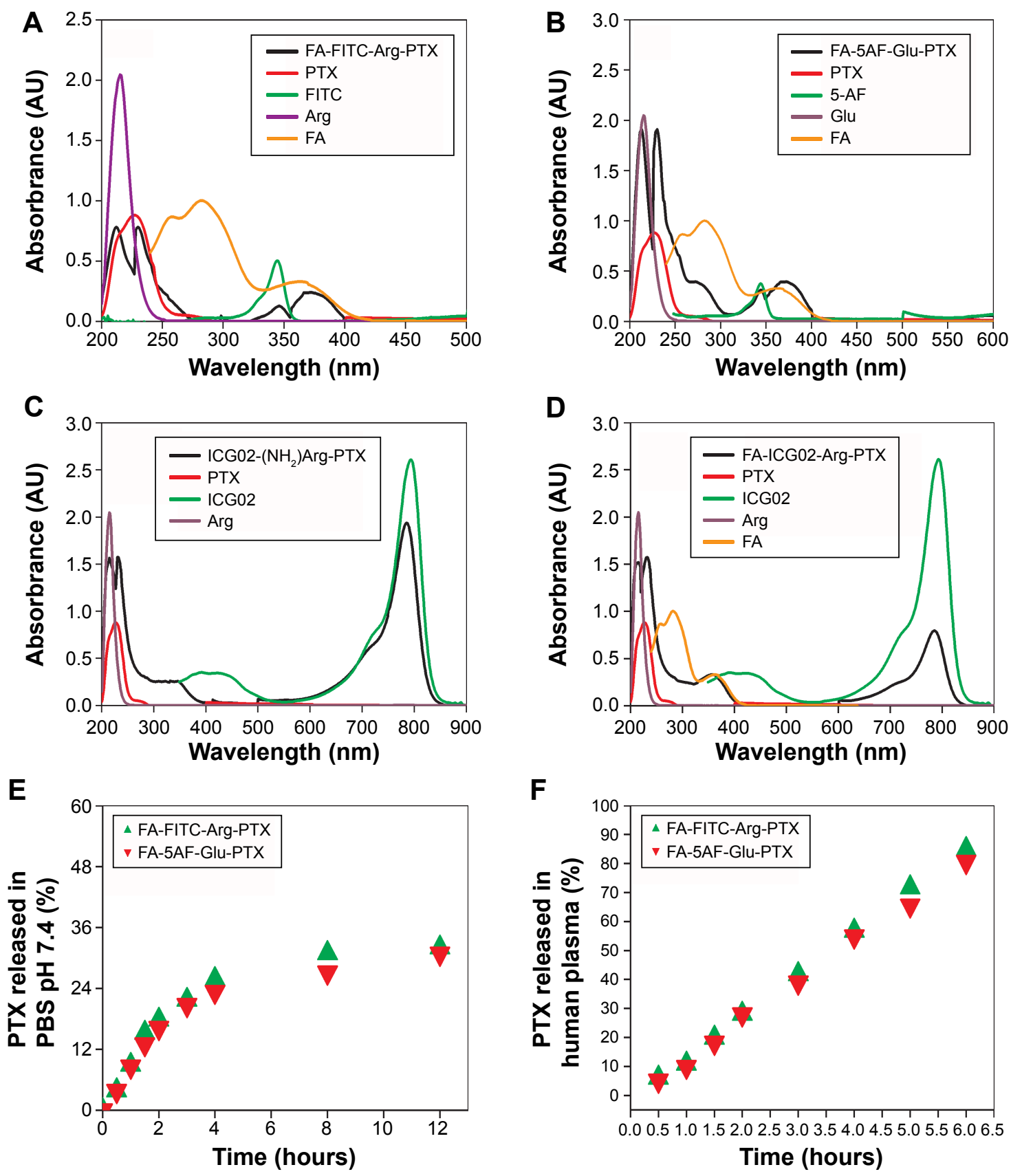

Figure 2 Characterization of multi-small molecule-conjugated paclitaxel prodrugs.

Notes: (A) Absorption peaks of FA-FITC-Arg-PTX prodrug formulation overlaps the peaks of FA, Arg, PTX, and FITC at $365 \mathrm{~nm}, 220 \mathrm{~nm}, 227 \mathrm{~nm}, 375 \mathrm{~nm}$, and $780 \mathrm{~nm}$, respectively. (B) Absorption spectra for the FA-5AF-Glu-PTX formulation. The absorption peaks at $365 \mathrm{~nm}, 220 \mathrm{~nm}, 227 \mathrm{~nm}$, and $465 \mathrm{~nm}$ represent absorption of FA, Glu, PTX, and 5AF, respectively. (C) Absorption spectra of ICG02-( $\left.\mathrm{NH}_{2}\right)$ Arg-PTX formulation at $220 \mathrm{~nm}, 227 \mathrm{~nm}$, and $780 \mathrm{~nm}$ represent absorption of Arg, FA, and ICGDer-02, respectively. (D) Absorption peaks of FA-ICG02-Arg-PTX formulation at $365 \mathrm{~nm}, 220 \mathrm{~nm}, 227 \mathrm{~nm}$, and $780 \mathrm{~nm}$ represent absorption of FA, Arg, PTX, and ICGDer-02, respectively. (E) Release of free PTX from FA-FITC-Arg-PTX and FA-5AF-Glu-PTX in phosphate-buffered saline. (F) Release of free PTX from FA-FITC-Arg-PTX and FA-5AF-Glu-PTX in human plasma.

Abbreviations: 5AF, 5-aminofluorescein; FA, folic acid; FITC, fluorescein isothiocyanate; PTX, paclitaxel; Arg, arginine; Glu, glutamic acid.

\section{Dynamics and targeting ability of multi- small molecule-loaded PTX in tumor- bearing mice}

MDA-MB-231 cells with relative overexpression of FR- $\alpha$ were used to investigate the dynamics and tumor targeting ability of multi-small molecule-loaded PTX. Representative near-infrared images after administration of ICG02-( $\left.\mathrm{NH}_{2}\right)$ Arg-PTX and FA-ICG02-Arg-PTX are shown in Figure 6A and B. The fluorescent ICG02-( $\left.\mathrm{NH}_{2}\right)$ Arg-PTX initially spread throughout the whole body at 


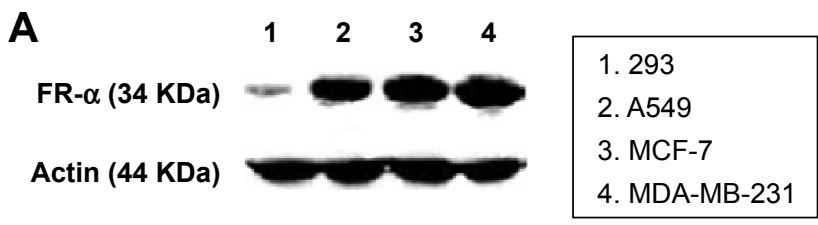

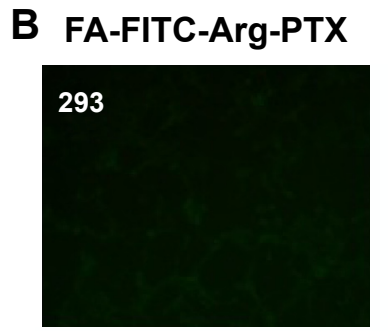
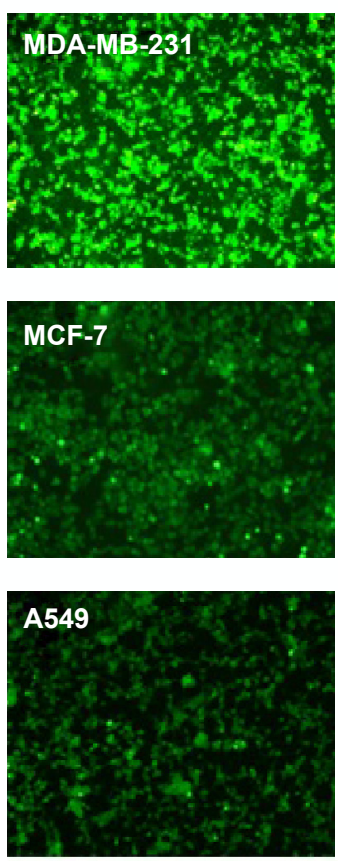

\section{FA-5AF-GIu-PTX}
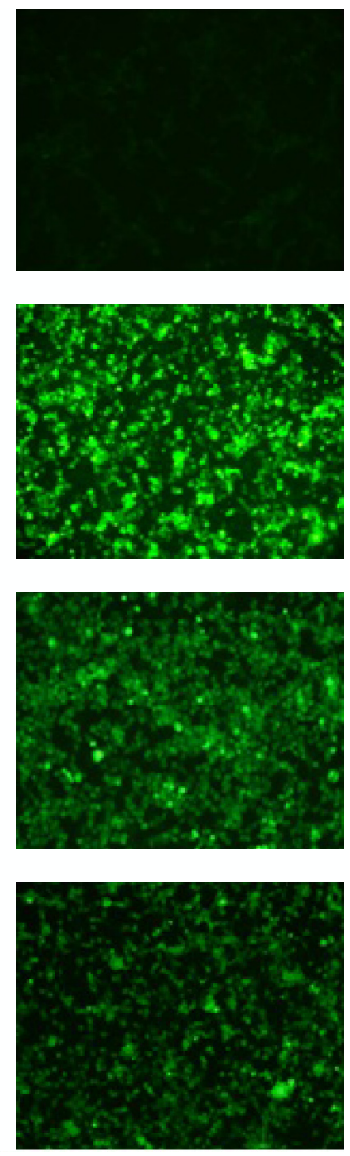

C
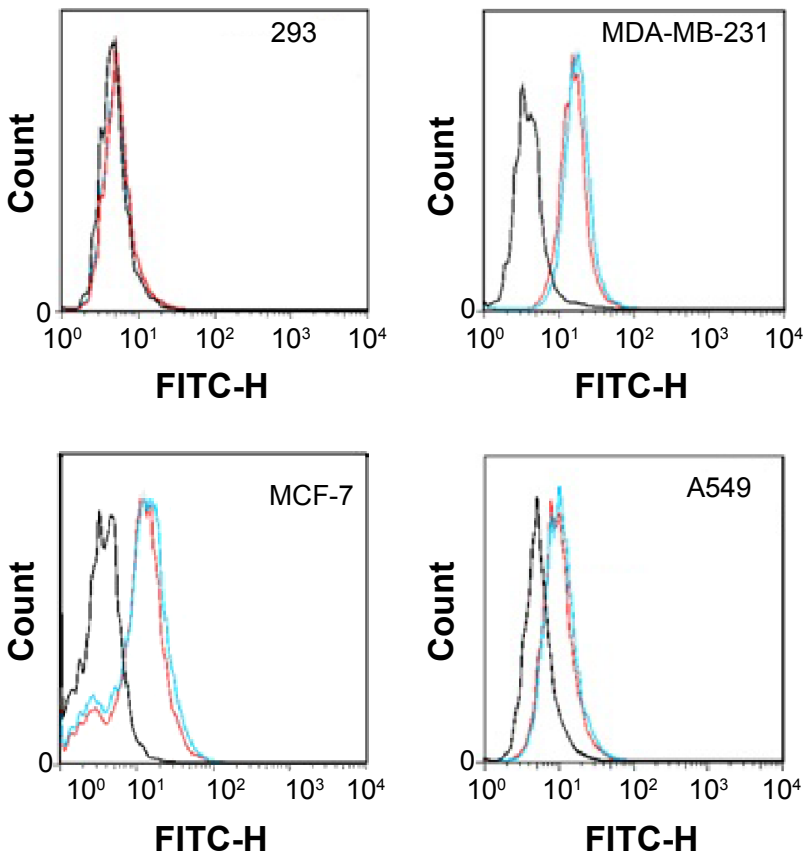

Figure 3 Targeting capability of fluorescence dye-labeled PTX prodrug formulations in different tumor cell lines with different FA- $\alpha$ receptor expression levels.

Notes: (A) Protein levels of FR- $\alpha$ in the tumor and normal cell lines were determined by Western blot. (B) Targeting ability of PTX prodrug formulations in MDAMB-23I, MCF-7, A549, and HEK293 cells. Tumor cells show increased uptake of PTX prodrug compared with the normal cell lines with low expression of FR protein. (C) Flow cytometric analysis of FA-modified PTX prodrug formulation in MDA-MB-23I, MCF-7, A549, and HEK293 cells. FA-FITC-Arg-PTX and FA-5AF-Glu-PTX prodrug formulations were taken up into the MDA-MB-23I cell lines at a rate of $89.6 \%$ and $85.9 \%$, respectively, but at a rate of only $2.1 \%$ and I.9\% in $\mathrm{HEK} 293$ cells. Abbreviations: 5AF, 5-aminofluorescein; FA, folic acid; FITC, fluorescein isothiocyanate; PTX, paclitaxel; FA- $\alpha$, folate receptor alpha.

about 30 minutes post-injection and gradually appeared in the tumor, as well as the organs of excretion, including the liver, gastrointestinal tract, and bladder. The fluorescent drug in the tumor gradually washed out, with a decrease in signals from the liver, gastrointestinal tract, and bladder. At 24 hours post-injection, the fluorescent probe has mostly cleared from the body (Figure 6A). The FA-ICG02-Arg-PTX initially distributed all over the body and was subsequently cleared via the hepatobiliary and renal pathways (Figure 6B). However, the tumor sites were identifiable 1 hour after injection of the probes. Over time, the drug increasingly accumulated in the tumors and the fluorescence intensity peaked at about 4 hours. The bright fluorescence signal in the tumor tissue gradually disappeared after 4 days (data not shown).

Tumor contrast as quantified by region of interest analysis of fluorescence intensity shown in Figure 6C indicates that the $\mathrm{T} / \mathrm{N}$ tissue ratio was $4.42 \pm 0.16$ at 1 hour post-injection of FA-ICG02-Arg-PTX, reaching a peak at 4 hours postinjection $(15.1 \pm 0.46)$ and slowly declined to $8.10 \pm 0.71$ by 48 hours. In contrast, MDA-MB-231 tumor-bearing mice intravenously injected with the ICG02-( $\left.\mathrm{NH}_{2}\right)$ Arg-PTX formulation showed a $\mathrm{T} / \mathrm{N}$ ratio of $3.24 \pm 0.33$ after 0.5 hours; uptake reached a peak of $4.87 \pm 0.42$ at 2 hours, and slowly 
A
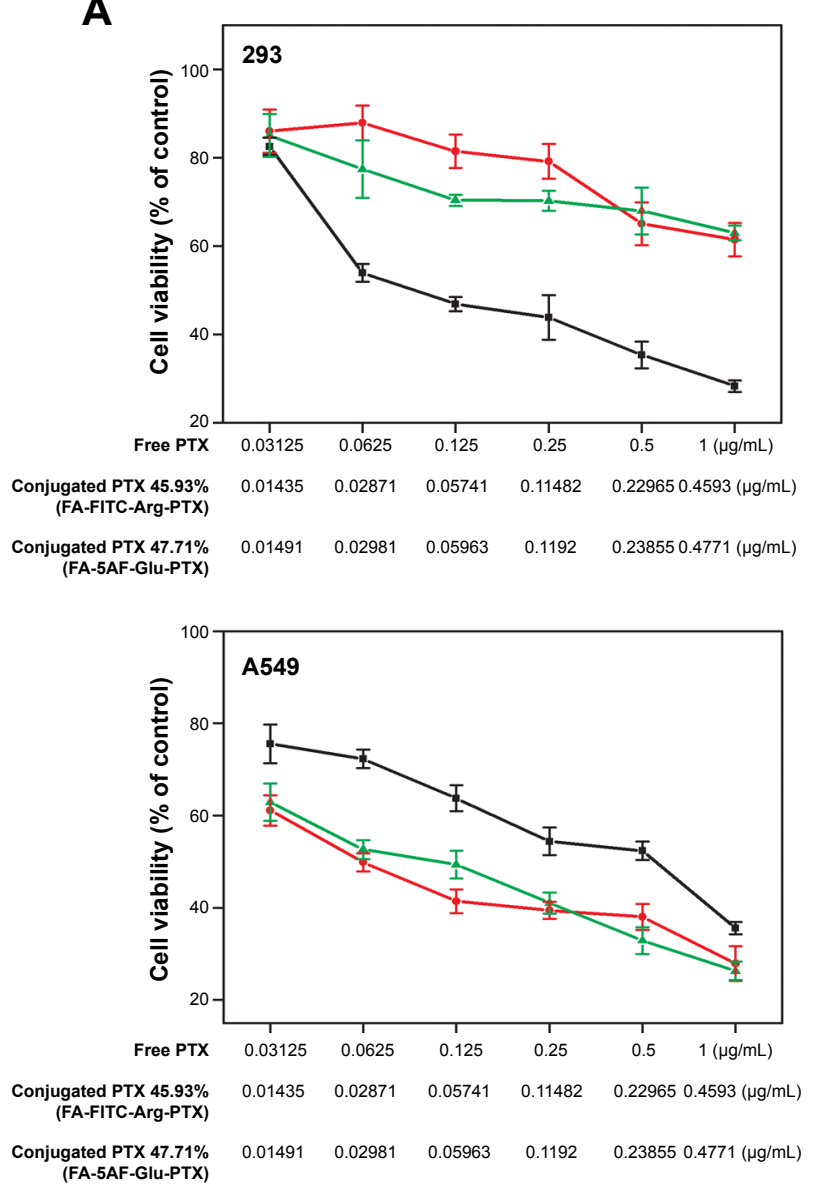

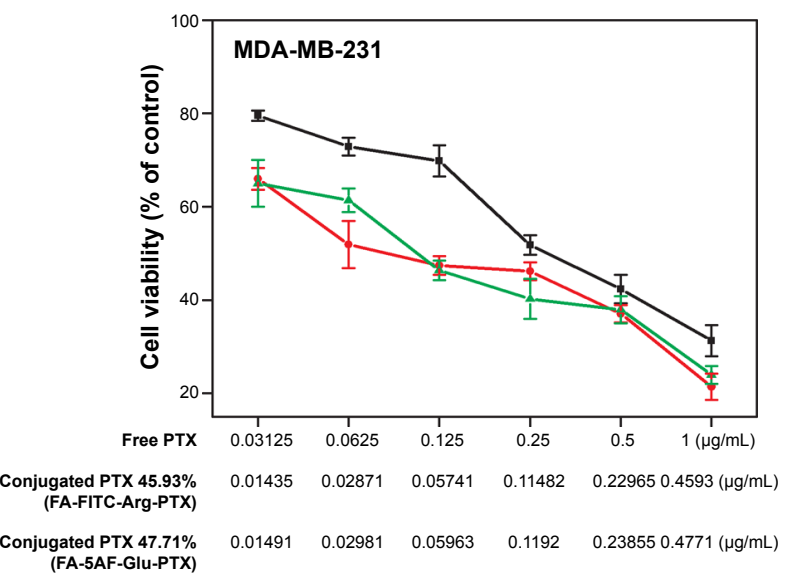

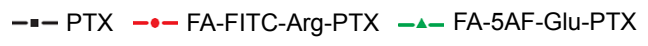
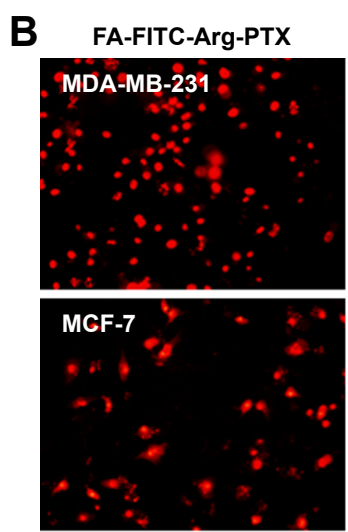

A549
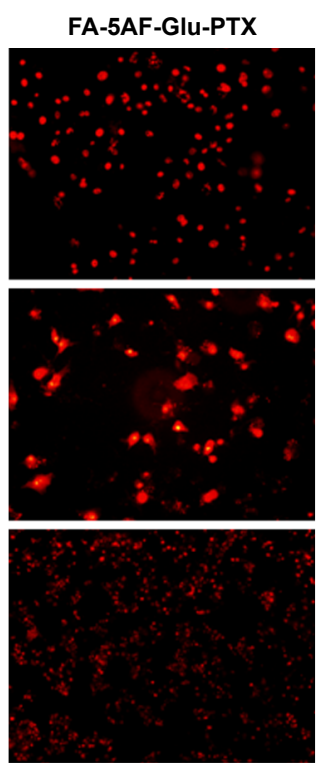
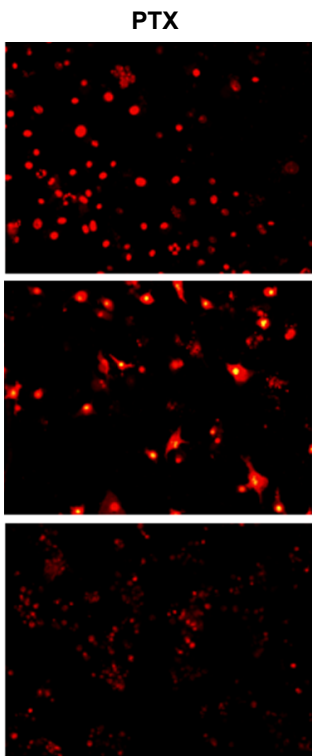

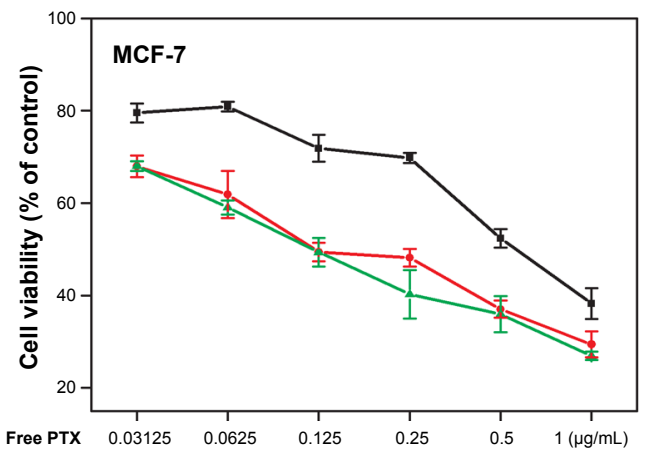

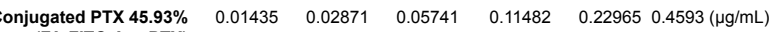
(FA-FITC-Arg-PTX)

gated PTX $47.71 \%$

$\begin{array}{llllll}0.01491 & 0.02981 & 0.05963 & 0.1192 & 0.23855 & 0.4771\end{array}(\mu \mathrm{g} / \mathrm{mL})$ 


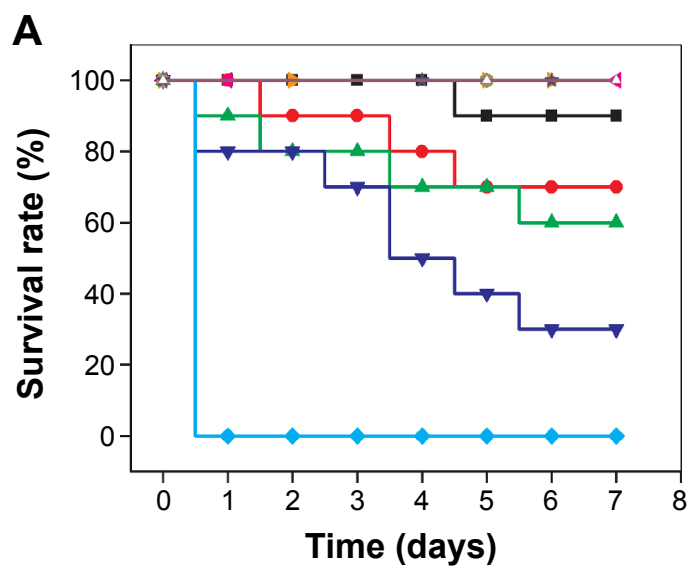

- PTX $(15 \mathrm{mg} / \mathrm{kg})$
- PTX $(20 \mathrm{mg} / \mathrm{kg})$
- PTX $(25 \mathrm{mg} / \mathrm{kg})$
- PTX $(35 \mathrm{mg} / \mathrm{kg})$
- PTX $(45 \mathrm{mg} / \mathrm{kg})$
- FA-FITC-Arg-PTX $(80 \mathrm{mg} / \mathrm{kg})$
- FA-FITC-Arg-PTX $(160 \mathrm{mg} / \mathrm{kg})$
$-\approx-$ FA-FITC-Arg-PTX $(200 \mathrm{mg} / \mathrm{kg})$
$-\triangle-$ FA-FITC-Arg-PTX $(280 \mathrm{mg} / \mathrm{kg})$
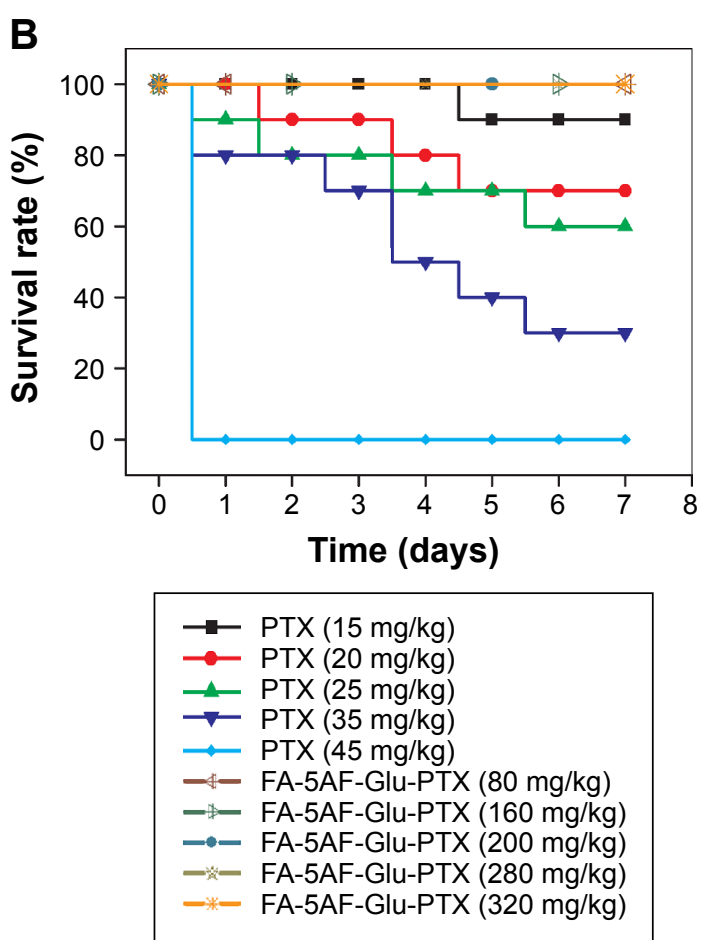

Figure 5 Acute toxicity of PTX, FA-FITC-Arg-PTX, and FA-5AF-Glu-PTX assessed by LD . $^{\circ}$

Notes: (A) Compared with PTX (15, 20, 25, 35, and $45 \mathrm{mg} / \mathrm{kg})$, FA-Arg-PTX-FITC (80, 160, 200, 280, and $320 \mathrm{mg} / \mathrm{kg})$ increased the survival rate in in normal mice. The survival rate of FA-Arg-PTX-FITC was $100 \%$ with different dose, LD $_{50}>320$ mg/kg. (B) Compared with PTX (I5, 20, 25, 35, and 45 mg/kg), FA-5AF-Glu-PTX (80, I60, 200, $280,320 \mathrm{mg} / \mathrm{kg}$ ) increased the survival rate in in normal mice. The survival rate of FA-5AF-Glu-PTX was $100 \%$ with different dose, $\mathrm{LD}_{50}>320 \mathrm{mg} / \mathrm{kg}(\mathrm{n}=10$ per group).

Abbreviations: 5AF, 5-aminofluorescein; FA, folic acid; FITC, fluorescein isothiocyanate; PTX, paclitaxel.

declined to $2.18 \pm 0.40$ by 4 hours. Statistical analysis indicated a significant difference in the T/N ratio in MDA-MB231 tumors for the two PTX drug formulations $(P<0.05)$. FA-ICG02-Arg-PTX could extend the drug residence time or drug concentration in tumor tissue.

On the basis of the above results, we euthanized the mice bearing MDA-MB-231 tumor xenografts at 4 hours after injection of FA-FITC-Arg-PTX or FA-5AF-Glu-PTX. All tissues were immediately excised for sectioning and were visualized by fluorescence microscopy. Representative images are shown in Figure 6D. Fluorescence images of tissue sections displayed the highest fluorescence signal in tumor tissues, and appeared in the organs of excretion, ie, the liver, gastrointestinal system, and bladder. The drug probably entered the liver and was subsequently transported to the gastrointestinal system. Another fraction of the drug was excreted by the kidney-bladder pathway. Similar results were seen in the in vivo and in vitro studies.

\section{In vivo therapeutic experiment}

The in vivo antitumor efficacy of PTX, FA-FITC-Arg-PTX, and FA-5AF-Glu-PTX was evaluated in MCF-7-tumorbearing mice and A549 tumor-bearing mice by measuring tumor growth rate and body weight. Figure 7A indicates that treatment with PBS produced the fastest tumor growth, while multi-small molecule-conjugated PTX inhibited tumor growth most effectively. MCF-7 tumor growth was inhibited at a rate of $57.63 \%$ and $54.02 \%$ after administration of FA-FITC-Arg-PTX and FA-5AF-Glu-PTX, respectively, which is higher than that of free PTX (about 38.16\%). The inhibition rate of the two prodrug (48.65\%/44.52\%)-treated A549 tumor was about 1.4/1.3 times higher than that of the free PTX-treated tumor (35.23\%, Figure 7).

Body weight loss in the PTX-treated mice bearing MCF-7 tumors was $3.88 \mathrm{~g}$, which was approximately $20 \%$ of their original body weight at the end of the treatment period (Figure 7B). A gradual increase in body weight in the PBS, FA-FITC-Arg-PTX and FA-5AF-Glu-PTX groups was observed during the treatment period. The decrease of body weight of the A549 group treated with PTX was $3.92 \mathrm{~g}$, about $25.34 \%$ of the original weight. Slightly reduction in body weight also occurred in the two groups of mice treated with FA-FITC-Arg-PTX/FA5AF-Glu-PTX (about 2\%, Figure 7D). These results suggest that conjugation of PTX could significantly decrease the toxicity of the free drug. 
A
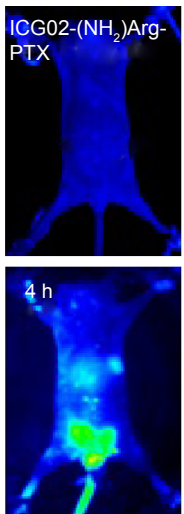

B
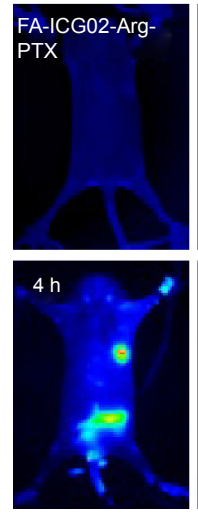

D
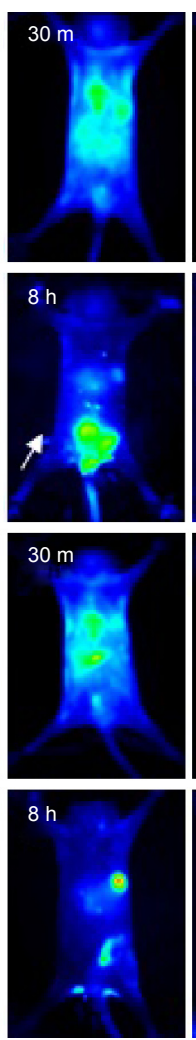
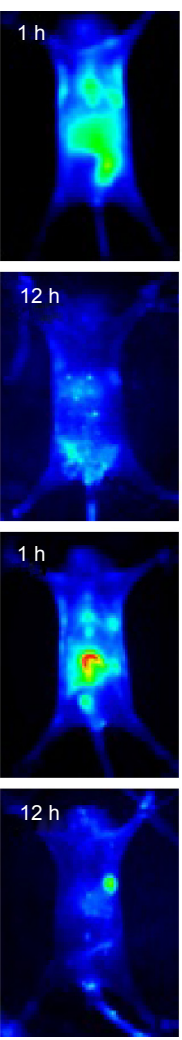

FA-FITC-Arg-PTX
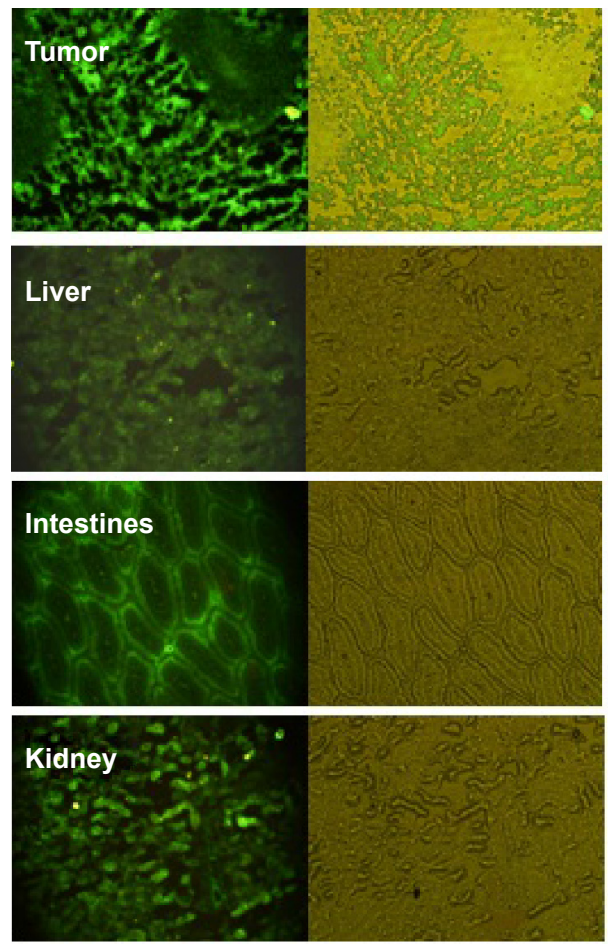
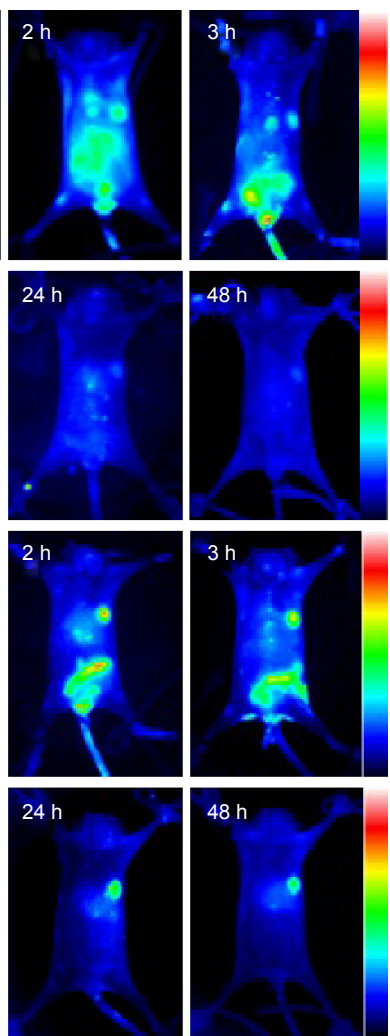
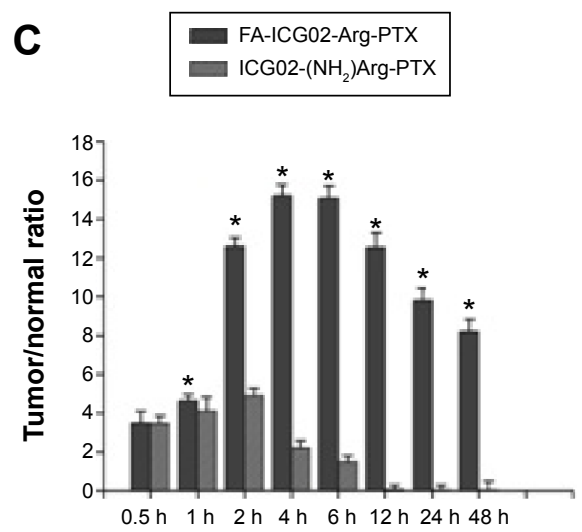

Time after injection (hours)

\section{FA-5AF-Glu-PTX}
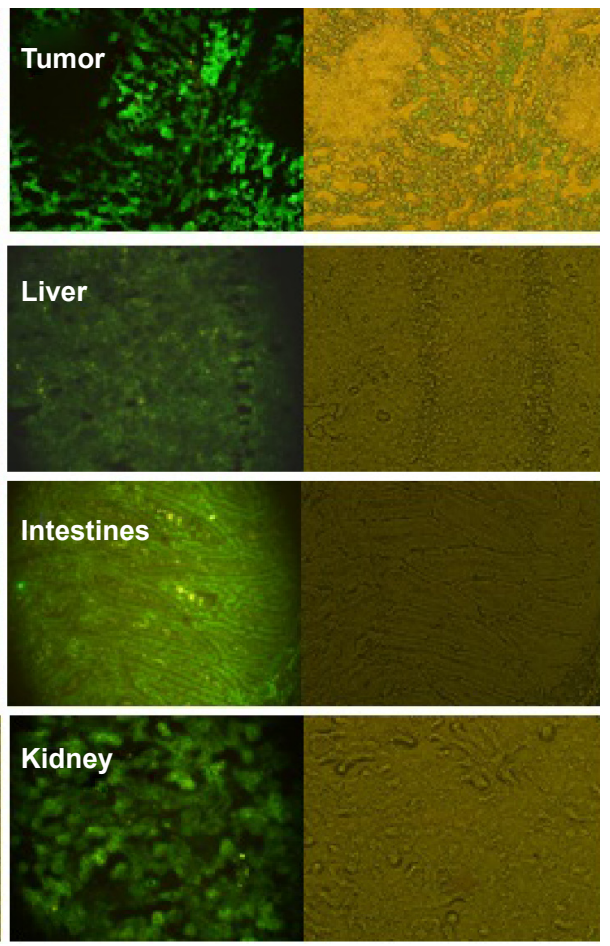

Figure 6 Dynamic behavior and targeting capability of the PTX prodrug formulations in MDA-MB-23I tumor-bearing mice.

Notes: (A) Images of the tumor-bearing mice after administration of ICG02-( $\left.\mathrm{NH}_{2}\right)$ Arg-PTX within 48 hours. (B) Images of the tumor-bearing mice after administration of FA-ICG02-Arg-PTX within 48 hours. (C) The T/N ratio in MDA-MB-23I tumor tissues for ICG02-(NH) Arg-PTX and FA-ICG02-Arg-PTX prodrug formulations. (D) Based on the targeting ability of PTX prodrugs, we euthanized the mice bearing MDA-MB-23I tumor xenografts at 4 hours post-injection of FA-FITC-Arg-PTX or FA-5AF-Glu-PTX and all tissues were immediately excised for sectioning and were visualized by fluorescence microscopy. *Statistical analysis indicated that there was a significant difference in the $\mathrm{T} / \mathrm{N}$ ratio in the MDA-MB-23I tumor tissues between the two prodrug formulations $(P<0.05)$. The data are shown as the mean \pm standard deviation ( $\mathrm{n}=5 \mathrm{per}$ group). Abbreviations: 5AF, 5-aminofluorescein; FA, folic acid; FITC, fluorescein isothiocyanate; PTX, paclitaxel; T/N, tumor-to-normal tissue; h, hour; m, minutes. 
A

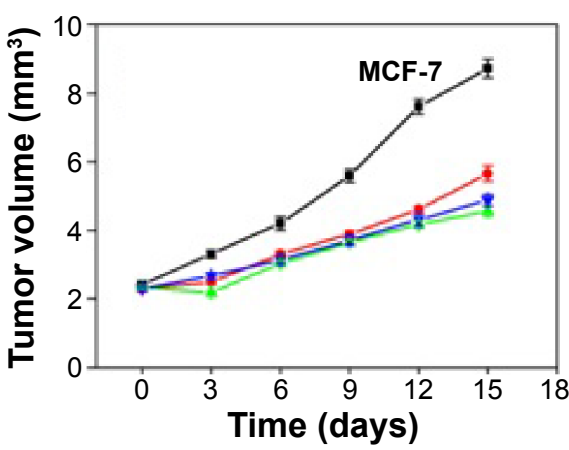

C

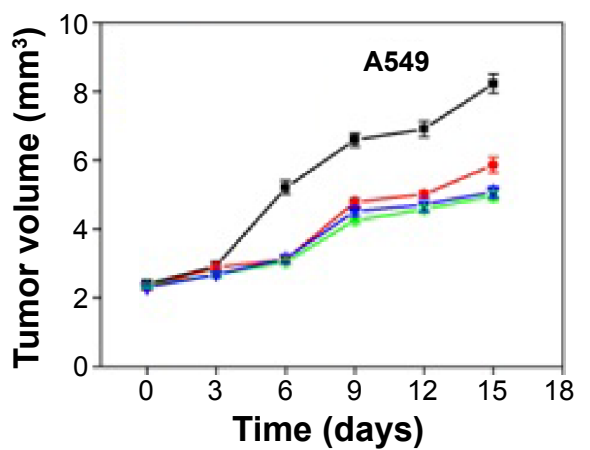

B

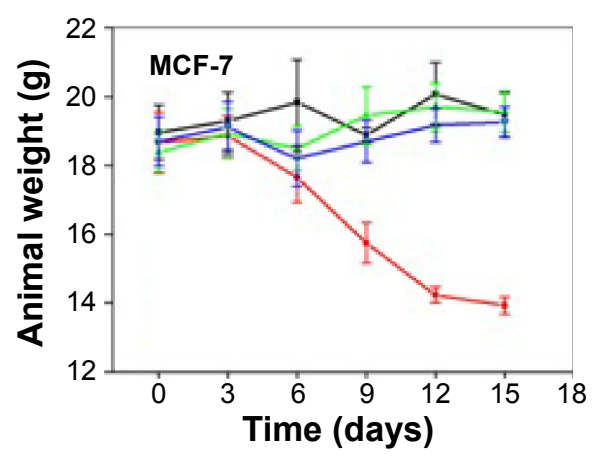

D

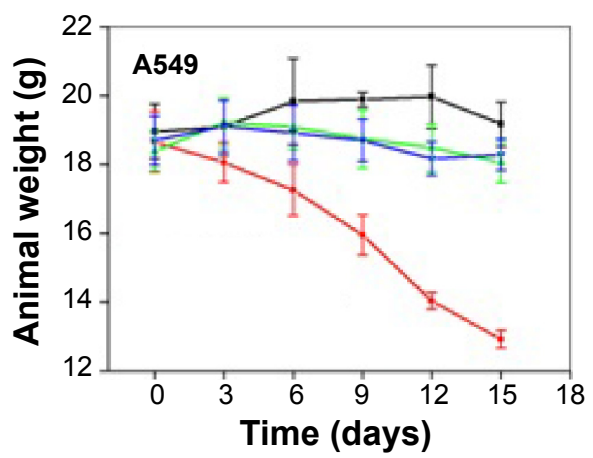

-i-Control =- PTX $=$ FA-FITC-Arg-PTX $-\%-$ FA-5AF-Glu-PTX

E
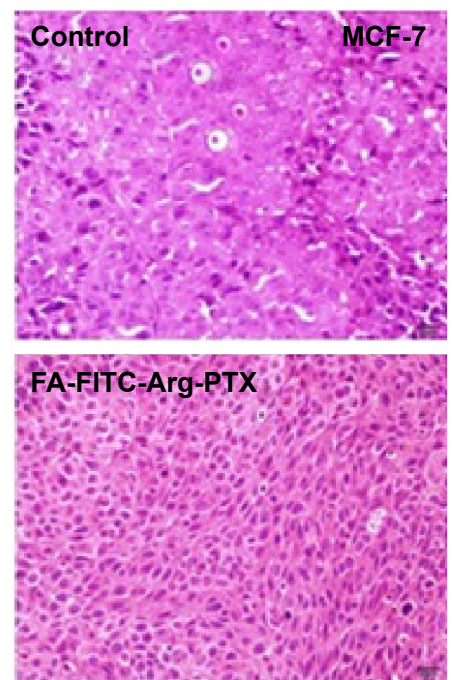
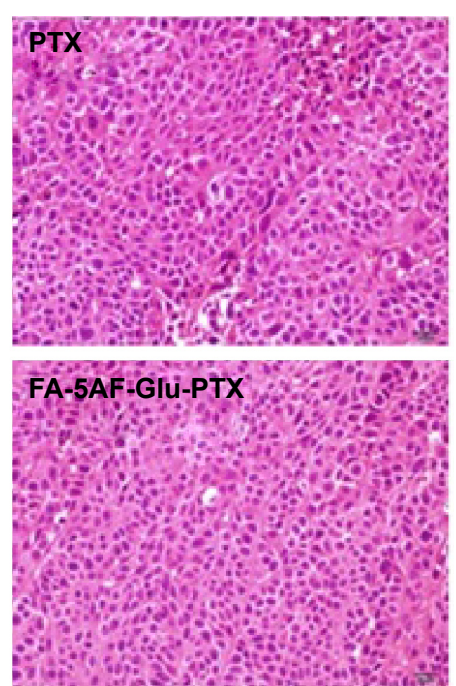

Figure 7 In vivo therapeutic experiment.

Notes: (A) Tumor volumes for MCF-7-bearing mice as a function of time (days). (B) Animal weights of MCF-7-bearing mice as a function of time (days). Data are shown as the mean $(n=6)$. (C) Tumor volumes for A549-bearing mice as a function of time (days). (D) Animal weights of A549-bearing mice as a function of time (days). Data are shown as the mean $(n=6)$. (E) Tissue sections of tumor excised from MCF-7-bearing nude mice I5 days after administration of PTX, FA-FITC-Arg-PTX, and FA-5AF-Glu-PTX. More than $98 \%$ of mice in the groups treated with PTX, FA-FITC-Arg-PTX, and FA-5AF-Glu-PTX showed tumor tissue with spotty necrosis, spherical cells, and loose order under higher than normal doses. (Magnification 400X).

Abbreviations: 5AF, 5-aminofluorescein; FA, folic acid; FITC, fluorescein isothiocyanate; PTX, paclitaxel.

To further evaluate the antitumor effect of PTX, FA-FITCArg-PTX, and FA-5AF-Glu-PTX in animals, the tumor tissues were excised for pathology. Figure 7E shows representative tissue sections from different mice groups. Tumor tissue in the PTX, FA-FITC-Arg-PTX, and FA-5AF-Glu-PTX groups exhibited spotty necrosis, spherical cells, and loose order. Finally, FA-FITC-Arg-PTX and FA-5AF-Glu-PTX groups possessed loose order in tumor tissue. However, no histological difference was observed in the different mice-bearing A549 tumor groups. All results confirmed that multi-small molecule-conjugation is the most effective tumorinhibiting strategy when compared with the other groups. 


\section{Discussion}

PTX is an antitumor compound, with high clinical efficacy. However, its low aqueous solubility remains a major problem, because it can lead to high toxicity and low bioavailability. The currently developed formulations of PTX indicate that these problems are still unresolved. ${ }^{28,29}$ In this study, we developed a new active vector mediating a multi-small moleculeconjugated PTX prodrug delivery system for targeted tumor therapy. Water-soluble small molecules, amino acids (Glu or Arg), FA, and fluorescent dye (FITC or 5AF), were successfully conjugated to PTX, and greatly enhanced the solubility of synthesized FA-Arg-PTX-FITC $(6.45 \pm 0.15 \mathrm{mg} / \mathrm{mL})$ and FA-Glu-PTX-5AF $(6.61 \pm 0.18 \mathrm{mg} / \mathrm{mL})$. The PTX loading rate of these two prodrugs reached $38.70 \% \pm 0.49 \%$ and $32.19 \% \pm 0.35 \%$, respectively. The release rate for free PTX from the conjugation was an important factor influencing therapeutic efficacy. As shown in Figure 2E, more of the two prodrugs FA-FITC-Arg-PTX and FA-5AF-Glu-PTX was released in human plasma than in PBS, indicating that the faster release of the PTX might be related to an enzyme in plasma. ${ }^{17}$ Interestingly, high PTX release rates occurred when the product accumulated in tumor cells/tissues (by 4 hours). The slight release of free PTX from the conjugation in PBS supports storage of the prodrug at $-20^{\circ} \mathrm{C}$.

The toxicity of PTX greatly affects its clinical utility. ${ }^{30} \mathrm{In}$ this study, we assessed the in vitro toxicity of the two prepared prodrugs in both tumor and normal cell lines (Figures 4A and 5). We found decreased cytotoxicity of PTX in both cell lines after multi-small molecule conjugation. In tumor cells, both FA-FITC-Arg-PTX and FA-5AF-Glu-PTX showed comparably strong toxicity (approximately $20 \%$ cell viability) at high doses, whereas multi-small molecule-conjugated PTX was much safer in normal cells. It can be easily understood that the cytotoxicity of PTX is higher in normal cells than in tumor cells given that proliferation rates are higher in tumor cells than in normal cells, as are FR- $\alpha$ protein expression levels, resulting in the different response to the lower dose treatment. ${ }^{31}$ Cell viability rates and FR- $\alpha$ receptor expression in MDA-MB-231, MCF-7, and A549 cells showed a statistically significant correlation between receptor protein expression and tumor cell targeting (Figure 4). The cytotoxicity of PTX and its conjugates was dose-dependent. In the in vivo acute toxicity study, the $\mathrm{LD}_{50}$ of free PTX was $25.48 \pm 0.17 \mathrm{mg} / \mathrm{kg}$, whereas the intravenous $\mathrm{LD}_{50}$ of each prodrug was greater than $320 \mathrm{mg} / \mathrm{kg}$. No obvious histological changes were found in either of the PTX prodrug formulations. The above results suggest that multi-small molecule-loaded PTX has lower toxicity than free PTX.
The targeting ability of drugs is also one of the important factors contributing to drug development and clinical application because higher targeting ability can increase therapeutic efficacy and reduce side effects. The cellular uptake ability of multi-small molecule-conjugated PTX was analyzed by qualitative and quantitative analysis (Figure 3 ). The percentage cell uptake in the tumor groups treated with FA-FITC-Arg-PTX (63.22\%-89.63\%) and FA-5AF-GluPTX (59.01\%-85.93\%) was much higher than that of normal cells ( $2.1 \%$ and $1.9 \%$, respectively). Our in vitro data clearly showed that the FA-FITC-Arg-PTX/FA-5AF-Glu-PTX prodrugs mediated by FA enhanced cellular uptake and antitumor activity. For the in vivo study, the time-dependent clearance of ICG02-( $\left.\mathrm{NH}_{2}\right)$ Arg-PTX displayed greater uptake of ICG02- $\left(\mathrm{NH}_{2}\right)$ Arg-PTX by the liver and intestines than by the tumor (Figure 6A). This result is consistent with the finding that PTX can pass through the enterohepatic circulation and undergo first pass metabolism in those organs. ${ }^{22}$ However, FA-ICG02-Arg-PTX rapidly accumulates in MDA-MB231 tumors by receptor-mediated uptake, reaching a peak after 4 hours after administration and maintaining a bright signal for up to 2 days. A more significant amount of FAICG02-Arg-PTX than ICG02-( $\left.\mathrm{NH}_{2}\right)$ Arg-PTX was observed to accumulate in tumor tissues with positive FR- $\alpha$ receptor expression (Figure 6B). Similar results were also shown in tissue sections treated with FA-FITC-Arg-PTX/FA-GluPTX-5AF at 4 hours post-injection (Figure 6D). The tumor targeting ability of the synthesized FA-FITC-Arg-PTX and FA-5AF-Glu-PTX was significantly improved by receptormediated uptake on imaging with a fluorescence microscope. These results indicate that PTX-loaded multi-small molecules improved the targeting ability of PTX for FR-positive tumors. Above all, tumor-targeted PTX-conjugated multi-small molecule delivery systems could enhance drug retention time and drug concentrations in tumor tissue.

The in vitro antitumor efficiency of multi-small molecule-conjugated PTX was confirmed by analysis of both cell viability and induction of apoptosis (Figure 4). The cell viability study showed that FA-FITC-Arg-PTX/ FA-5AF-Glu-PTX achieved a higher tumor cell inhibition rate when compared with free PTX. The percentage of late apoptotic (PI-positive) cells in the tumor groups was higher. The number of necrotic/dead cells (Q4) was 36.5\% for FA-FITC-Arg-PTX and 34.1\% for FA-5AF-Glu-PTX, compared with only $25.8 \%$ in MDA-MB-231 cells treated with treated free PTX. We also tested the therapeutic activity of these FR- $\alpha$ sensitive prodrugs by injecting the prodrugs and free PTX into tumor-bearing mice five times within 
15 days at a dose of $5 \mathrm{mg} / \mathrm{kg}$ for the conjugated PTX and $5 \mathrm{mg} / \mathrm{kg}$ for the free PTX. Our data indicate that the released multi-small molecule-conjugated PTX was still active after the FR-mediated, which is consistent with the indication that esterification at $\mathrm{C}-2^{\prime}$ did not significantly influence the activity of PTXs. Tumor growth in the FR- $\alpha$-mediated prodrug group was significantly inhibited when compared with free PTX. It is also notable that inhibition of tumor growth was closely correlated with the significant apoptosis seen in the tumor tissues (Figure 7). No significant changes were observed after prodrugs treatment with the FR-mediated small-preparation in terms of mouse body weight. The mice treated with free PTX showed a significantly smaller weight decrease (approximately 25.34\%) and higher tumor growth volume (approximately 30\%). In contrast, the multi-small molecule carriers improved the water solubility, pharmacokinetic profile, and biodistribution of PTX, resulting in less toxicity. Hematoxylin and eosin staining did not show histological signs of toxicity in the major organs from mice treated with the FR- $\alpha$ mediated multi-small molecule preparation. However, necrotic areas were clearly present in tumors treated with the FR- $\alpha$-sensitive multi-small molecule preparations (Figure 7), in agreement with the antitumor effects observed in Figure 4. The high therapeutic index of the two prodrugs is most likely a result of collaborative functions, including the effect of the water solubility of the multi-small molecules (Arg/Glu, FA, FITC/5AF), the "stealth" characteristics of the amino acid ester, FA/FR- $\alpha$-mediated intracellular drug delivery, and enhanced penetration/diffusion.

\section{Conclusion}

Taken together, the multi-small molecule carrier for PTX used in the current study can be potentially used to increase the therapeutic efficacy of PTX concomitantly with high targeting ability, a high therapeutic index, and low side effects. Furthermore, compared with previous macromolecular PTX formulations, multi-small molecular-conjugated PTX prodrugs also demonstrated a higher water solubility, loading rate, targeting ability, and antitumor activity, as well as lower toxicity. These results suggest that the use of this platform would accelerate the clinical development of this PTX formulation and could potentially provide the basis for a prospective targeting drug delivery system for tumor therapy.

\section{Acknowledgments}

The authors thank Wei Zhu and Xiuqin Yang for their expert assistance with the animal experiments, and are grateful for the grants received from the Natural Science Foundation
Committee of China (NSFC81220108012, 661335007, $81171395,81328012)$, the Natural Science Foundation Committee of Anhui Province (1308085MH136, KJ2014A249, KJ2013A242, KJ2013A243, 2013SQRL086ZD), and the Science Foundation of Suzhou University (2012jb04, 2014jb05, 2014jb06).

\section{Author contributions}

LS, YG conceived and designed the study. LS, GG, and WC developed the study methodology. LS, CW, SL, and LX were responsible for acquisition of the data, including acquisition of the study animals and providing facilities. LS and LZ analyzed and interpreted the data, and performed the statistical analysis. Writing, review, and revision of the paper was undertaken by LS and ML. The study was supervised by LS. All authors contributed toward data analysis, drafting and critically revising the paper and agree to be accountable for all aspects of the work.

\section{Disclosure}

The authors report no conflicts of interest in this work.

\section{References}

1. Llinas A, Glen RC, Goodman JM. Solubility challenge: can you predict solubilities of thirty-two molecules using a database of one hundred reliable measurements. J Chem Inf Model. 2008;48:1289-12303.

2. Wenlock MC, Austin RP, Barton P, et al. Prodrug approaches for enhancing the bioavailability of drugs with low solubility. J Med Chem. 2003; 46:1250-1256.

3. Williams HD, Trevaskis NL, Charman SA, et al. Strategies to address low drug solubility in discovery and development. Pharmacol Rev. 2013; 65:315-499.

4. Kim EJ, Bhuniya S, Lee H, et al. An activatable prodrug for the treatment of metastatic tumors. J Am Chem Soc. 2014;136:1388-1394.

5. Singla AK, Garg A, Aggarwal D. Paclitaxel and its formulations. Int $J$ Pharm. 2002;235:179-192.

6. Dorr RT. Pharmacology and toxicology of Cremophor EL diluent. Ann Pharmacother. 1994;28:S11-S14.

7. Holvoet C, Vander Heyden Y, Lories G, Plaizier-Vercammen J. Preparation and evaluation of paclitaxel-containing liposomes. Pharmazie. 2007; 2:126-132.

8. Duong HH, Yung LY. Synergistic co-delivery of doxorubicin and paclitaxel using multi-functional micelles for cancer treatment. Int $J$ Pharm. 2013;54:486-495.

9. Shahin M, Ahmed S, Kaur K, Lavasanifar A. Decoration of polymeric micelles with cancer-specific peptide ligands for active targeting of paclitaxel. Biomaterials. 2011;32:5123-5133.

10. Yezhelyev M, Yacoub R, O'Regan R. Inorganic nanoparticles for predictive oncology of breast cancer. Nanomedicine (Lond). 2009;4: 83-103.

11. Paál K, Müller J, Hegedûs L. High affinity binding of paclitaxel to human serum albumin. Eur J Biochem. 2001;268:2187-2191.

12. Wang H, Zhao Y, Wu Y, et al. Enhanced anti-tumor efficacy by codelivery of doxorubicin and paclitaxel with amphiphilic methoxy PEGPLGA copolymer nanoparticles. Biomaterials. 2011;32:8281-8290.

13. Gupta N, Hatoum H, Dy GK. First line treatment of advanced nonsmall-cell lung cancer-specific focus on albumin bound paclitaxel. Int J Nanomedicine. 2014;9:209-221. 
14. Wohl AR, Michel AR, Kalscheuer S, Macosko CW, Panyam J, Hoye TR. Silicate esters of paclitaxel and docetaxel: synthesis, hydrophobicity, hydrolytic stability, cytotoxicity, and prodrug potential. JMed Chem. 2014; 57:2368-2379.

15. Ma P, Mumper RJ. Paclitaxel nano-delivery systems: a comprehensive review. J Nanomed Nanotechnol. 2013;18:1000164.

16. Shan L, Cui S, Du C, et al. A paclitaxel-conjugated adenovirus vector for targeted drug delivery for tumor therapy. Biomaterials. 2012;33: 146-162.

17. Hasabelnaby S, Goudah A, Agarwal HK, abd Alla MS, Tjarks W. Synthesis, chemical and enzymatic hydrolysis, and aqueous solubility of amino acid ester prodrugs of 3-carboranyl thymidine analogs for boron neutron capture therapy of brain tumors. Eur J Med Chem. 2012;55: 325-334.

18. Arote RB, Hwang SK, Lim HT, et al. The therapeutic efficiency of FPPEA/TAM67 gene complexese via folate receptor-mediated endocytosis in a xenograft mice model. Biomaterials. 2010;31:2435-2445.

19. Leanmon CP, Low PS. Delivery of macromolecules into living cells: a method that exploits folate receptor endocytosis. Proc Natl Acad Sci US A. 1991;88:5572-5576.

20. Jhaveri MS, Rait AS, Chung KN, Trepel JB, Chang EH. Antisense oligonucleotides targeted to the human folate receptor inhibit breast cancer cell growth and sensitize the cells to doxorubicin treatment Mol Cancer Ther. 2004;3:1505-1512.

21. Wu M, Gunning W, Ratnam M. Expression of folate receptor type alpha in relation to cell type, malignancy, and differentiation in ovary, uterus, and cervix. Cancer Epidemiol Biomarkers Prev. 1999;8:775-782.

22. Shan L, Xue J, Guo J, Qian Z, Achilefu S, Gu Y. Improved targeting of ligand-modified adenovirus as a new near infrared fluorescence tumor imaging probe. Bioconjug Chem. 2011;22:567-581.
23. Zhang J, Chen H, Xu L, Gu Y. The targeted behavior of thermally responsive nanohydrogel evaluated by NIR system in mouse model. J Control Release. 2008;131:34-40.

24. Amaechi BT, Ramalingam K. Evaluation of fluorescence imaging with reflectance enhancement technology for early caries detection. Am J Dent. 2014;27:111-116.

25. Mondal SB, Gao S, Zhu N, Liang R, Gruev V, Achilefu S. Real-time fluorescence image-guided oncologic surgery. Adv Cancer Res. 2014; 124:171-211.

26. Greenwald RB, Pendri A, Bolikal D. Highly water soluble Taxol derivatives: 7-polyethylene glycol carbamates and carbonates. J Org Chem. 1995;60:331-336.

27. Yoshida M, Maehara Y, Sugimachi K. MST-16, a novel bis-dioxopiperazine anticancer agent, ameliorates doxorubicin-induced acute toxicity while maintaining antitumor efficacy. Clin Cancer Res. 1999;5: 4295-4300.

28. Guillemard V, Saragovi HU. Taxane-antibody conjugates afford potent cytotoxicity, enhanced solubility, and tumor target selectivity. Cancer Res. 2001;61:694-699.

29. Boztas AO, Karakuzu O, Galante G, et al. Synergistic interaction of paclitaxel and curcumin with cyclodextrin polymer complexation in human cancer cells. Mol Pharm. 2013;10:76-83.

30. Tsukiyama I, Takeuchi M, Abe F, et al. De-alcoholization of paclitaxel injection for clinical application. Anticancer Res. 2011;31:4339-4346.

31. Bandara NA, Hansen MJ, Low PS. Effect of receptor occupancy on folate receptor internalization. Mol Pharm. 2014;11:56-66. 


\section{Supplementary materials}

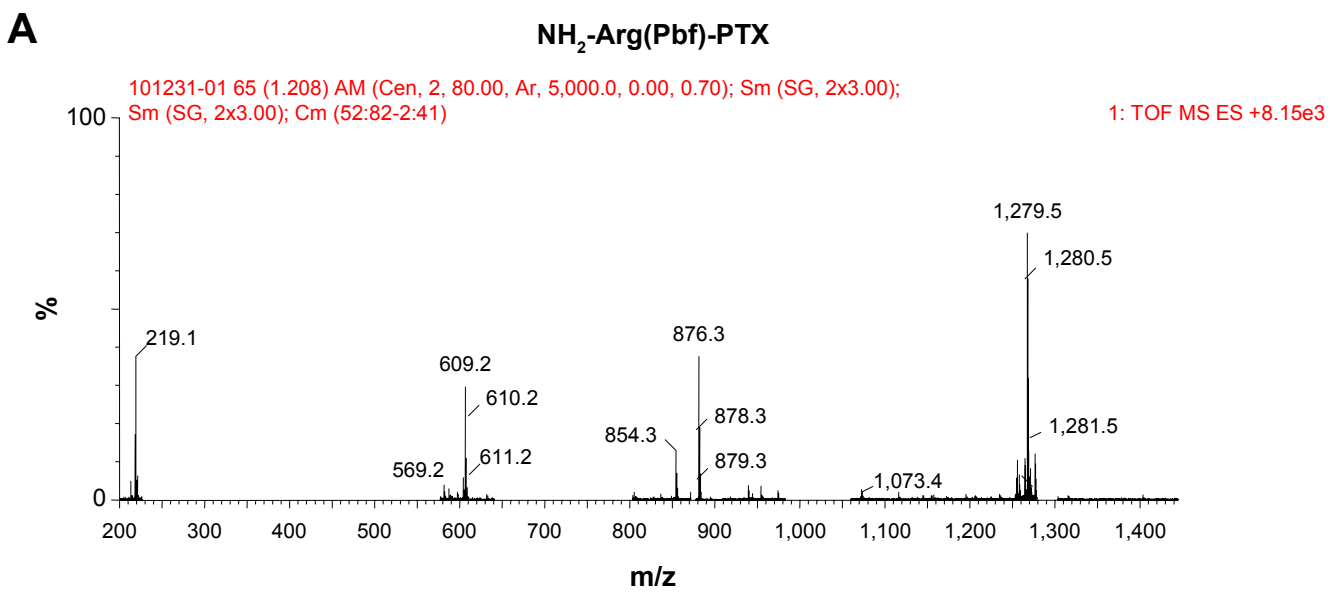

B

FA-Arg( $\left.\mathrm{NH}_{2}\right)$-PTX

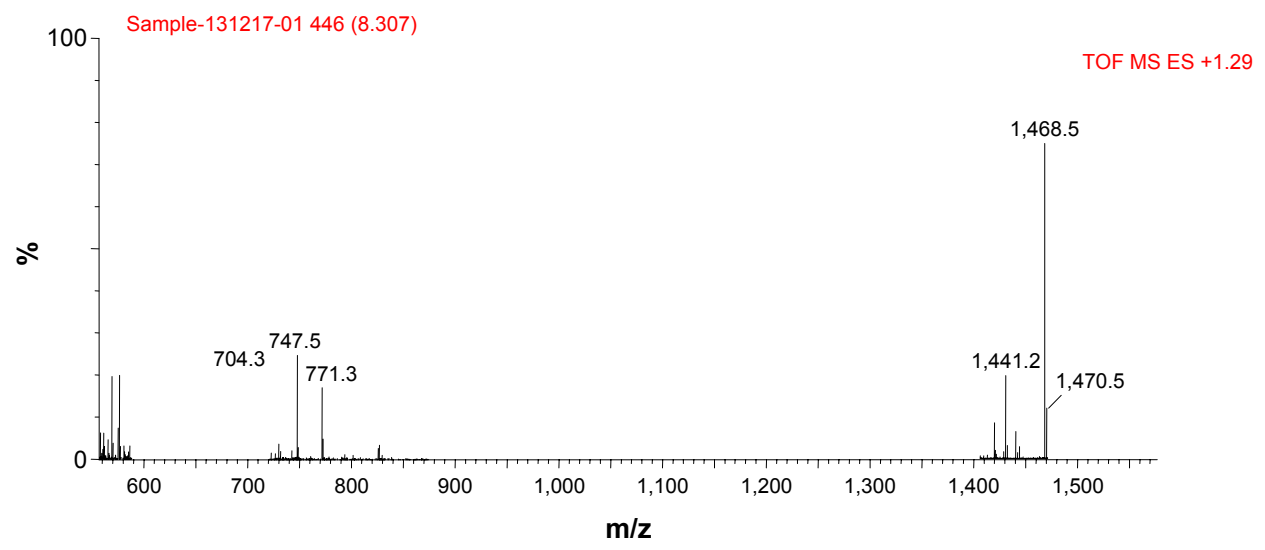

C

\section{$\mathbf{N H}_{2}$-Glu(tBut)-PTX} 100609-02 78 (1.110) AM (Cen, 2, 80.00, Ar, 5,000.0, 0.00, 0.70);

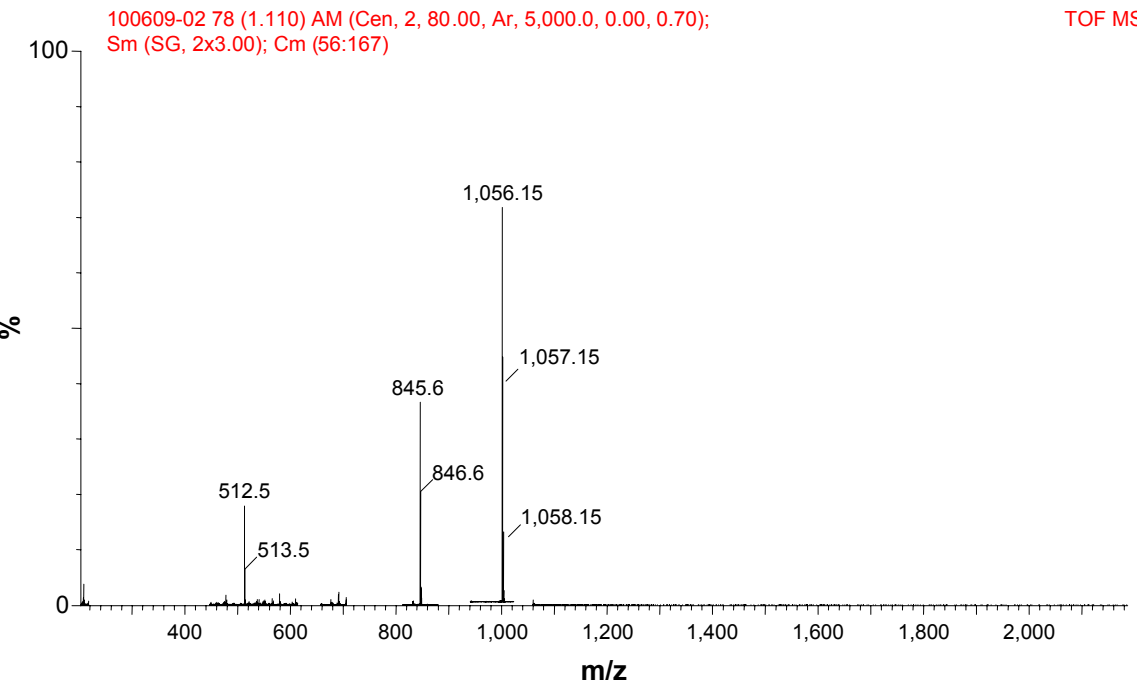

Figure SI (Continued) 
D

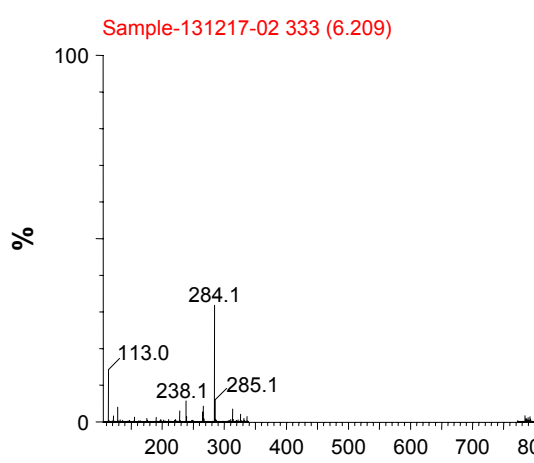

\section{FA-Glu(COOH)-PTX}

TOF MS ES +4.63e3

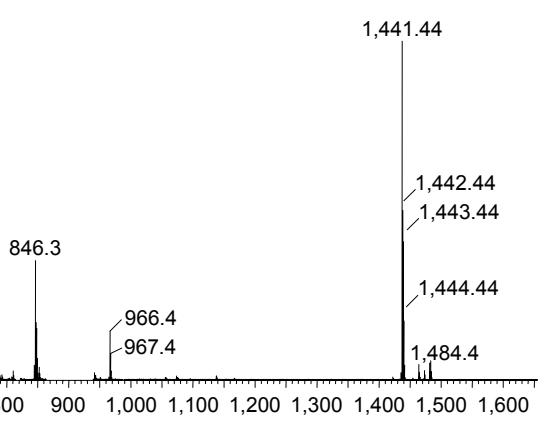

$\mathrm{m} / \mathbf{z}$

Figure SI Characterization of nanocarrier-conjugated intermediate compound.

Notes: $(\mathbf{A}) \mathrm{NH}_{2}-\operatorname{Arg}(\mathrm{Pbf})-\mathrm{PTX}$ (theoretically calculated molecular weight I,280.43): MS (ESI, m/z) I,279.43 ([M + H] $]^{+}$. (B) FA-Arg(NH $)$-PTX (theoretically calculated molecular weight I,469.5I): MS (ESI, m/z) I,468.5I ([M + H] $]^{+}$). (C) $\mathrm{NH}_{2}$-Glu(tBut)-PTX (theoretically calculated molecular weight I,057.I5): MS (ESI, m/z) I,056.I5 ([M + $\mathrm{H}]^{+}$). (D) FA-Glu(COOH)-PTX (theoretically calculated molecular weight I,442.44): MS (ESI, m/z) I,44I.44 ([M + H $\left.]^{+}\right)$.

Abbreviations: ESI, electrospray ionization; FA, folic acid; MS, mass spectrometry; PTX, paclitaxel; TOF, time of flight.

A

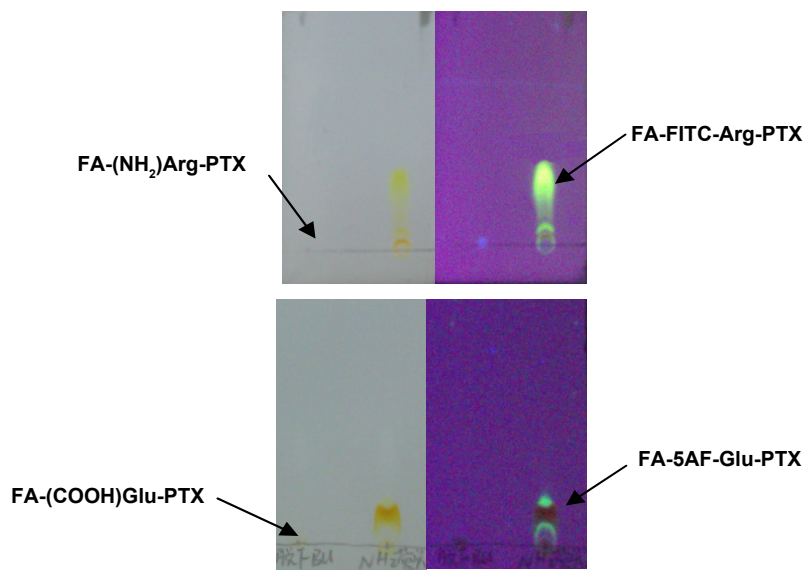

B

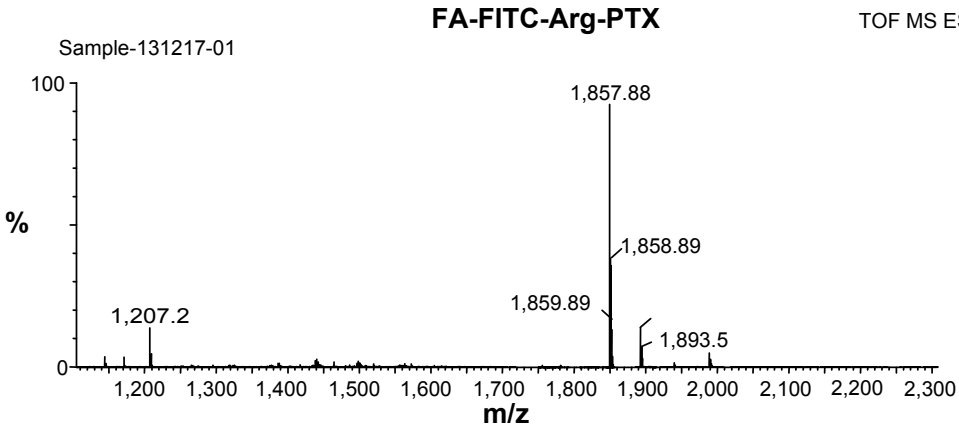

FA-5AF-Glu-PTX TOF MS ES $+4.73 \mathrm{e} 3$

Sample-131217-04

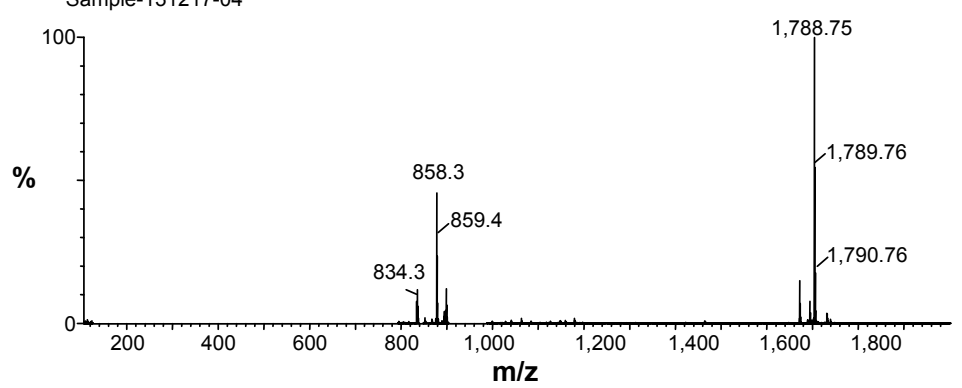

Figure S2 (Continued) 
C

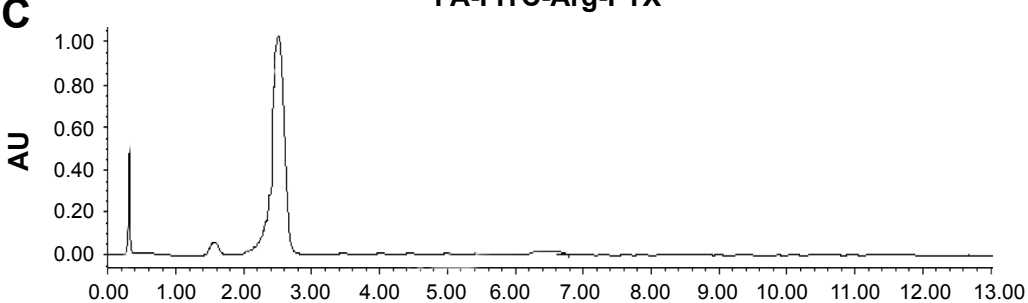

FA-FITC-Arg-PTX

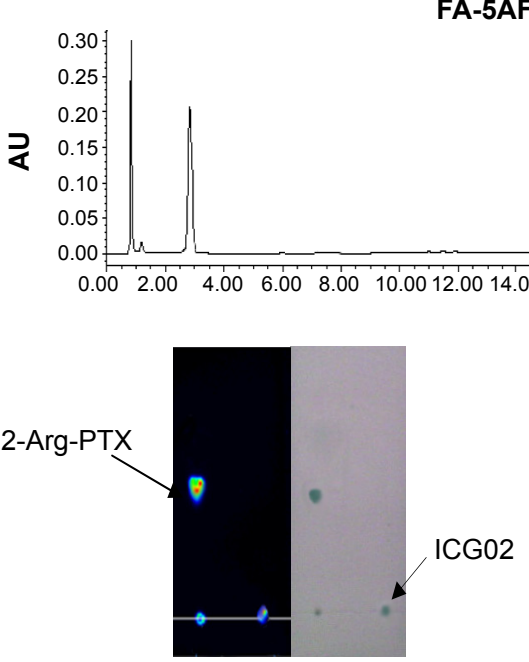

FA-5AF-Glu-PTX

D

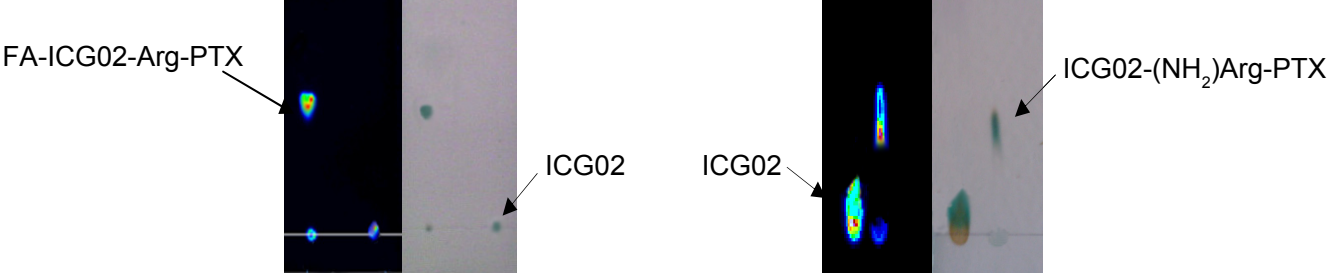

Figure S2 Characterization of nanocarrier-conjugated paclitaxel prodrugs.

Notes: (A) Fluorescence of FITC/5AF can be observed from thin layer chromatography of purified FA-FITC-Arg-PTX/FA-5AF-Glu-PTX using a fluorescence imaging system. (B) FA-FITC-Arg-PTX (theoretically calculated molecular weight I,859.88): MS (ESI, m/z) I,858.88 ([M + H] $]^{+}$). FA-5AF-Glu-PTX (theoretically calculated molecular weight I,790.75): MS (ESI, m/z) I,789.75 ([M+ H] $]^{+}$). (C) High-performance liquid chromatography of FA-FITC-Arg-PTX and FA-5AF-Glu-PTX prodrugs. (D) Fluorescence of ICG02 can be observed from the band of purified ICG02-( $\left.\mathrm{NH}_{2}\right)$ Arg-PTX using a near-infrared imaging system. Fluorescence of ICG02 can be observed from the band of purified FA-ICG02-Arg-PTX using the near-infrared imaging system.

Abbreviations: 5AF, 5-aminofluorescein; ESI, electrospray ionization; FA, folic acid; FITC, fluorescein isothiocyanate; MS, mass spectrometry; PTX, paclitaxel.

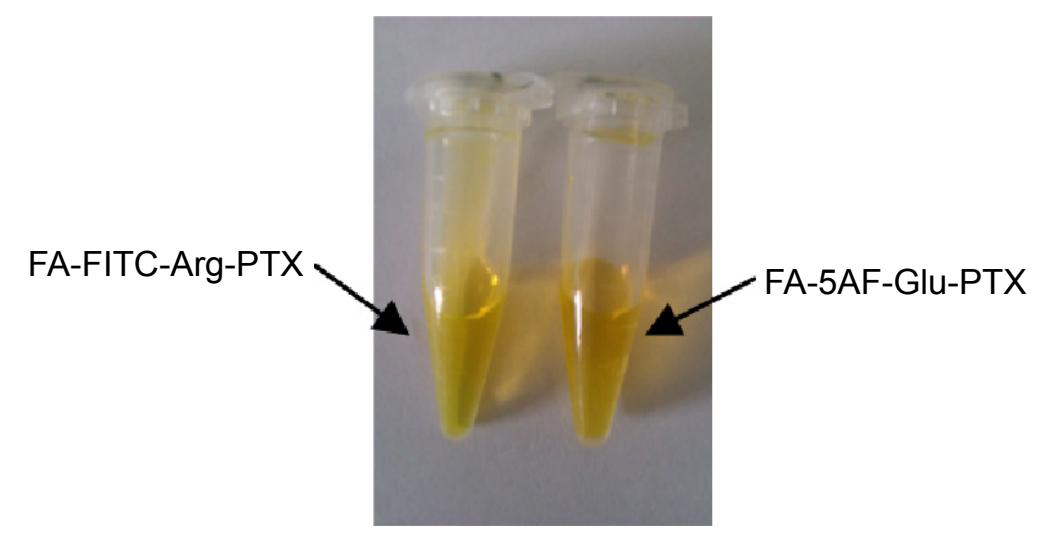

Figure S3 Aqueous solubility of multi-small molecule-conjugated PTX prodrugs.

Notes: The direct observation methods were used in the solubility calculations for the PTX prodrugs, FA-FITC-Arg-PTX (6.45 $\pm 0.15 \mathrm{mg} / \mathrm{mL}$, $\mathrm{n}=4)$ and FA-5AF-Glu-PTX $(6.4 \mathrm{I} \pm 0.18 \mathrm{mg} / \mathrm{mL}, \mathrm{n}=4)$.

Abbreviations: FA, folic acid; FITC, fluorescein isothiocyanate; PTX, paclitaxel. 


\section{A}

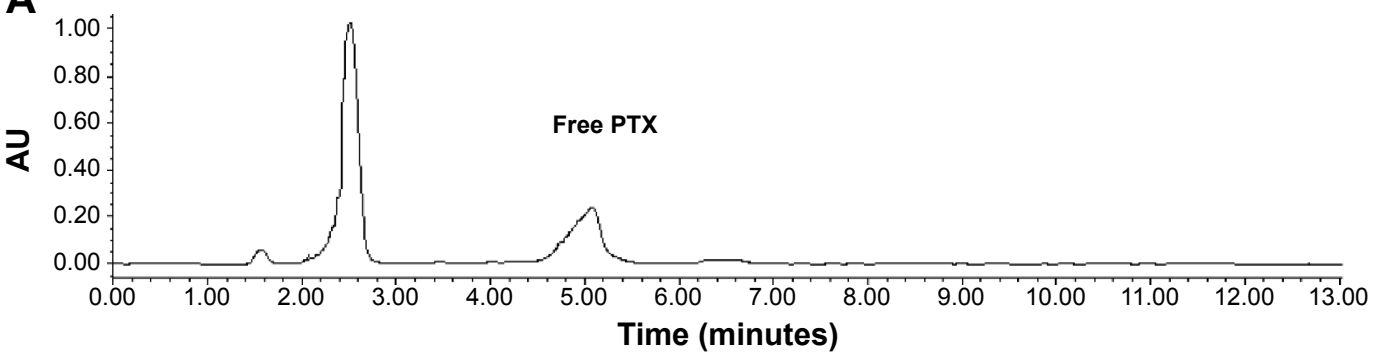

B

FA-5AF-Glu-PTX
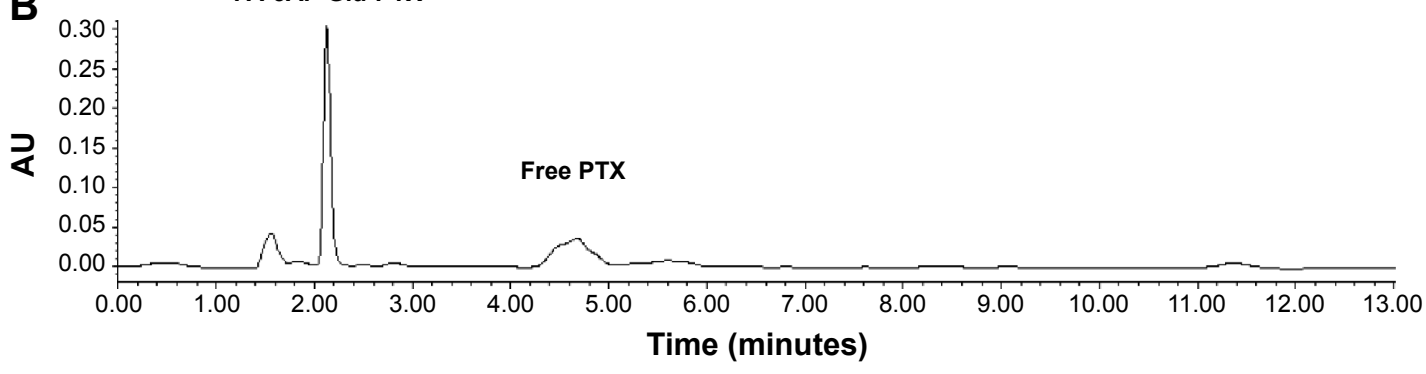

Figure S4 Release of PTX from FA-FITC-Arg-PTX and FA-5AF-Glu-PTX according to incubation time in phosphate-buffered saline ( $\mathrm{pH} 7.4$ ) or human plasma at $37^{\circ} \mathrm{C}$. Notes: (A) HPLC for incubation of FA-FITC-Arg-PTX in human plasma at $37^{\circ} \mathrm{C}$, showing the peak for free PTX at 4 hours. (B) HPLC for incubation of FA-5AF-Glu-PTX in human plasma, showing the peak for free PTX at 4 hours.

Abbreviations: 5AF, 5-aminofluorescein; FA, folic acid; FITC, fluorescein isothiocyanate; HPLC, high-performance liquid chromatography; PTX, paclitaxel.

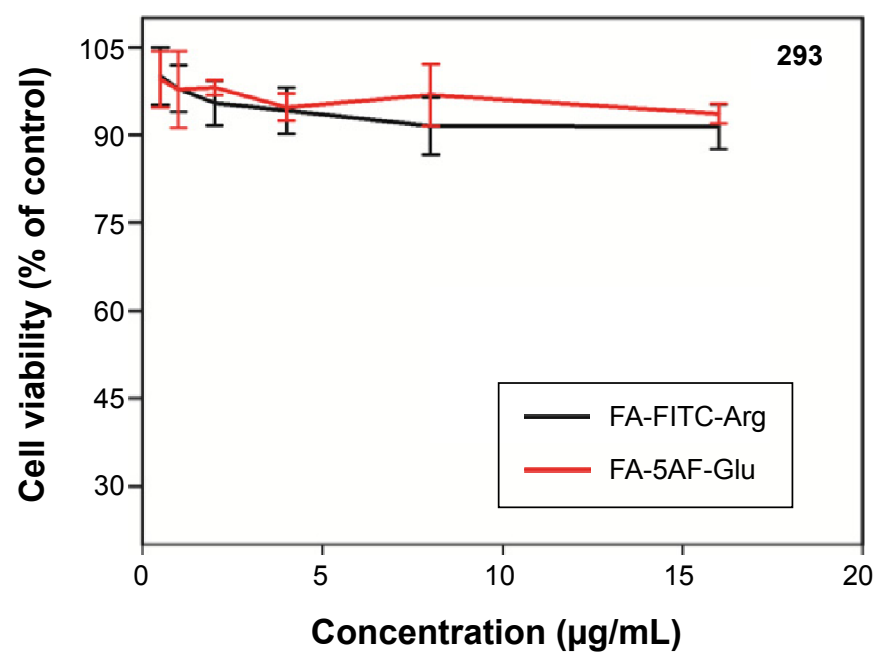

Figure S5 A cell viability ratio assay was used to qualitatively determine the cytotoxicity of FA-FITC-Arg and FA-5AF-Glu in a normal HEK293 cell line. (MTT assay, $\mathrm{n}=6$ ). Abbreviations: 5AF, 5-aminofluorescein; FA, folic acid; FITC, fluorescein isothiocyanate; PTX, paclitaxel.

\section{Publish your work in this journal}

The International Journal of Nanomedicine is an international, peerreviewed journal focusing on the application of nanotechnology in diagnostics, therapeutics, and drug delivery systems throughout the biomedical field. This journal is indexed on PubMed Central, MedLine, CAS, SciSearch $\AA$, Current Contents ${ }^{\circledR} /$ Clinical Medicine,
Journal Citation Reports/Science Edition, EMBase, Scopus and the Elsevier Bibliographic databases. The manuscript management system is completely online and includes a very quick and fair peer-review system, which is all easy to use. Visit http://www.dovepress.com/ testimonials.php to read real quotes from published authors. 